Review

\title{
Dynamic Contrast-Enhanced Magnetic Resonance Imaging (DCE-MRI) in Preclinical Studies of Antivascular Treatments
}

\section{Thomas Nielsen *, Thomas Wittenborn and Michael R. Horsman}

Department of Experimental Clinical Oncology, Aarhus University Hospital, DK-8000 Aarhus C, Denmark; E-Mails: wittenborn@oncology.dk (T.W.); mike@oncology.dk (M.R.H.)

* Author to whom correspondence should be addressed; E-Mail: thomas@oncology.dk; Tel.: +45-78463589; Fax: +45-86197109

Received: 29 June 2012; in revised form: 29 October 2012 / Accepted: 30 October 2012 / Published: 7 November 2012

\begin{abstract}
Antivascular treatments can either be antiangiogenic or targeting established tumour vasculature. These treatments affect the tumour microvasculature and microenvironment but may not change clinical measures like tumour volume and growth. In research on antivascular treatments, information on the tumour vasculature is therefore essential. Preclinical research is often used for optimization of antivascular drugs alone or in combined treatments. Dynamic contrast-enhanced magnetic resonance imaging (DCE-MRI) is an in vivo imaging method providing vascular information, which has become an important tool in both preclinical and clinical research. This review discusses common DCE-MRI imaging protocols and analysis methods and provides an overview of preclinical research on antivascular treatments utilizing DCE-MRI.
\end{abstract}

Keywords: DCE-MRI; angiogenesis inhibitors; vascular disrupting agents; preclinical studies

\section{Introduction}

\subsection{Tumour Microvasculature and Antivascular Treatments}

It is now well established that for virtually all solid tumours to grow they must develop their own functional blood supply [1,2]. They do this from the normal host vessels by the process of angiogenesis [3,4]. Once established, the neo-vasculature not only supplies tumour cells with essential oxygen and nutrients [5], it is also the principal vehicle for metastatic spread [6]. However, the 
neo-vasculature formed is a somewhat primitive and chaotic system which is structurally and functionally abnormal when compared to the host vasculature from which it develops [5]. As a result, areas form within the tumour which become oxygen deficient, nutrient deprived and highly acidic [5]. These adverse microenvironmental conditions not only play a significant role in influencing tumour response to conventional therapy [5,7], they also influence malignant progression in terms of making the primary tumour more aggressive and increasing its metastatic potential $[7,8]$.

The importance of the tumour neo-vasculature in all these aspects makes it an excellent target for therapy and two major therapeutic approaches have now emerged $[9,10]$. One focuses on controlling tumour blood vessel development by inhibiting angiogenesis. Various angiogenesis inhibitors (AIs) have now been identified, each affecting at least one of the several important stages of angiogenesis. The principal targets are the angiogenic factors, which play the most significant role in neo-vascularization [11], especially vascular endothelial growth factor (VEGF), which is essential for endothelial cell proliferation and blood vessel formation [11,12]. The AIs that target VEGF include monoclonal antibodies and inhibitors of endothelial cell receptor-associated tyrosine kinase activity [13-16]. Other approaches target the various physical steps in the angiogenesis process including basement membrane degradation, endothelial cell migration, endothelial cell proliferation, and tube formation [13-16]. Many of these anti-angiogenic therapies have undergone clinical evaluation $[13,15,17,18]$. The other major approach for targeting tumour vasculature involves compromising the function of the already established tumour blood vessels using so called vascular disrupting agents (VDAs). These include physical treatments like hyperthermia, photodynamic therapy (PDT) and even radiation; biological response modifiers; cytokines; certain chemotherapeutic drugs; and various ligand-based approaches that selectively bind to tumour vessels [10,19-22]. However, the approaches that have received the greatest attention involve small molecule drugs [22]. These include flavonoid derivatives that target endothelial cells through a cascade of direct and indirect effects that include the induction of cytokines leading to the induction of haemorrhagic necrosis [23,24]. It also includes tubulin-binding agents that selectively disrupt the cytoskeleton of proliferating endothelial cells, resulting in endothelial cell shape changes and subsequent thrombus formation and vascular collapse [24]. Both types of small molecular drugs have been shown to have potent anti-vascular and anti-tumour efficacy in a wide variety of preclinical models and the lead agents have also undergone clinical evaluation [20].

\subsection{In vivo Imaging of Antivascular Treatments}

The inadequate vasculature is the main cause of the disadvantageous tumour microenvironment, and information about the vasculature has been shown to be of prognostic value. Microvascular density (MVD) as an estimate of angiogenesis has been shown to be prognostic of metastatic disease and overall and disease specific survival in some malignant diseases [25-27]. Angiogenic factors, especially VEGF, have also been shown to be prognostic. VEGF has been significantly correlated with disease-specific survival in patients with various cancers, for example prostate cancer [28] and breast cancer (for review concerning the latter, see [29]).

The above assays are immunohistochemical, and noninvasive in vivo assays are hence desirable for prognosis assessment and therapeutic guidance. Noninvasive vascular information is of further 
relevance in evaluating antivascular treatments as they have the vasculature as the main target. Many immunohistological methods (e.g., MVD based on endothelial staining) do not take into account that a varying degree of tumour neovasculature is non-functional [30]. Whether information on all vasculature, functional vasculature, or both is important depends on the particular study. Assessing functional vasculature has been done using functional vascular staining and radiolabelled iodoantipyrine (IAP). Microenvironmental changes induced by vascular disrupting agents may indeed potentiate the clinical outcome when combined with other treatments. Imaging techniques may detect vascular changes and provide evidence of this beneficial action. This noninvasive vascular information may also prove important in optimizing such treatments. In radiation therapy research, the suggested effect on vasculature [31,32] may also be evaluated by the same imaging modalities.

Several imaging modalities can provide in vivo information about vasculature [33]. These include dynamic methods in ultrasonography [34,35], computed tomography (CT) [36], positron emission tomography (PET) [37], bioluminescence imaging [35], and magnetic resonance imaging (MRI). MRI has been proven useful as a noninvasive and nonionizing method for acquiring information about tumour microvasculature, and it offers several different methods for obtaining vascular information. Issues regarding the use of MRI in assessing the clinical effect of vascular targeting treatments are discussed in [38]. The MRI methods include arterial spin labelling (ASL), dynamic susceptibility contrast MRI (DSC-MRI), blood oxygenation level dependent (BOLD) imaging, and dynamic contrast enhanced MRI (DCE-MRI). ASL does not involve use of contrast agent, but it relies on a small signal and provides only perfusion information [39-41]. DSC-MRI uses first-pass bolus tracking of contrast agent [42,43]. This method gives information about relative perfusion, blood volume, and mean transit time. It is possible to also estimate average vessel size [44]. The susceptibility contrast relies on the contrast agent remaining intravascular, and the method is mostly used in the brain where the blood-brain-barrier prevents extravasation of small contrast agents. Both ASL and DSC-MRI give relative measures. A static susceptibility contrast approach is estimation of the transverse relaxation times $\mathrm{T}_{2}$ and $\mathrm{T}_{2}{ }^{*}$ before and after injecting a high-molecular-weight contrast agent, which acts as a blood pool agent (BPA) remaining intravascular at a constant concentration. This strategy allows estimation of relative blood volume and average vessel size $[45,46]$. Susceptibility contrast information on functional blood volume can also be obtained by BOLD by manipulating levels of endogenous deoxygenated haemoglobin, which is paramagnetic like the mentioned contrast agents [30].

DCE-MRI is widely used in both preclinical and clinical oncology for obtaining vascular information, and it is easily implementable on most MR scanners. DCE-MRI parameters have been correlated both with immunohistochemical assays and with outcome, for a review of studies, see [47]. Because of its extensive use in preclinical assessment of antivascular treatments, DCE-MRI was chosen as imaging modality for this review.

\section{DCE-MRI}

\subsection{Principle}

DCE-MRI is based on dynamic $\mathrm{T}_{1}$-weighted imaging of contrast agent extravasation over several minutes often with lower time resolution than needed to track a first-pass bolus. Often, a fast spoiled 
gradient echo sequence is used. Historically, increased blood vessel permeability in brain lesions and tumours can be detected by static imaging of contrast agent accumulation in a time window following contrast agent administration [48-50]. Analysis of dynamic data provides additional information. Many analysis approaches and parameters exist, but extravasation, interstitial volume, and sometimes blood volume are the main information obtained. The extravasation information depends on both perfusion and permeability, and separation of these parameters is difficult. However, this is a novel research area [51-53].

\subsection{Semiquantitative Analysis}

The dynamic data can be analysed either voxel-wise, or the average signal in a region of interest (ROI) can be calculated for analysis. Analysis methods can be separated into semi-quantitative approaches or quantitative models. From signal-time curves, semi-quantitative parameters like initial area under the curve (IAUC) for 60 or $90 \mathrm{~s}$, maximum signal enhancement, and time-to-peak can be calculated. With correctly chosen sequence parameters, the relative signal is linearly proportional to the contrast agent concentration, which facilitates comparison between studies [54]. The signal-time curves can also be converted to concentration-time curves if the contrast agent's relaxivity $r_{1}$, i.e., the ability to shorten relaxation time $T_{1}$, is known and the initial $T_{1}$ is estimated or another calibration is performed. This assumes a linear relaxivity and fast water-exchange between tissue compartments. Corresponding semi-quantitative analysis can be done on concentration-time-curves, but the parameters then involve quantitative concentrations. IAUC from concentration-time curves is a simple and robust estimate of vascularisation, and it is easily comparable between studies. However, the initial signal originates from several physiological properties including blood volume, perfusion, vessel permeability, and interstitial volume.

\subsection{Model Analysis}

The model analyses attempt to separate different physiological information from the concentration-time curves. Different models have been utilized, and often they involve freely diffusible tracer kinetics developed for non-imaging methods [55-58]. Tofts et al. compared three different models [59] by Tofts and Kermode [60], Larsson et al. [61], and Brix et al. [62] and discussed their assumptions and differences in the information they provide. Also the Patlak plot has been utilized for DCE-MRI analysis [63]. A consensus kinetic two-compartment model based on the model by Tofts and Kermode with standardization of parameters and units has been published by leading researchers [64]. The model describes the transport of contrast agent between the blood plasma and extravascular extracellular compartments, and it estimates the volume transfer constant between blood plasma and extravascular extracellular space, $K^{\text {trans }}$, the rate constant between extravascular extracellular space and blood plasma, $k_{\mathrm{ep}}$, and the volume of extravascular extracellular space per unit volume of tissue, $v_{\mathrm{e}}=K^{\text {trans }} / k_{\mathrm{ep}}$ by fitting the obtained contrast-time-curves to the model Equation:

$$
C_{t}(t)=K^{\text {trans }} \int_{0}^{t} C_{p}(\tau) e^{-k_{e p}(t-\tau)} d \tau
$$


where $C_{\mathrm{t}}(\mathrm{t})$ is the tissue concentration of Gd-DTPA, and $C_{\mathrm{p}}(\mathrm{t})$ is the plasma concentration of Gd-DTPA. The model is often extended to also estimate $v_{\mathrm{p}}$, which is otherwise assumed to be zero:

$$
C_{t}(t)=K^{\text {trans }} \int_{0}^{t} C_{p}(\tau) e^{-k_{e p}(t-\tau)} d \tau+v_{p} C_{p}(t)
$$

The Patlak model has been extended to also include the transfer rate from the extravascular extracellular compartment to the plasma compartment, and this model is similar to the extended Toft's model (Equation 2) $[65,66] . C_{\mathrm{p}}(\mathrm{t})$ can be measured from the dynamic images, but this is not trivial because of partial volume-effects and inflow-effects [67]. Tofts and Kermode [60] have utilized an assumed human input function, which is a model fit to experimental clinical data by Weinmann et al. [68] Similar model input functions exist for animal models, for example rats [69,70] and mice [71]. Another approach is the use of reference tissue in the dynamic images [72,73].

\subsection{Contrast Agents}

Differently sized contrast agents are used for DCE-MRI. The low-molecular Gd-DTPA leaks from physiological blood vessels outside the brain and to a larger extent from hyper-permeable tumour blood vessels. BPAs remain intravascular in healthy tissue, but often extravasate in tumours, however at a longer time-scale than low-molecular contrast agents. Blood vessel permeability is size-dependent such that both the vessel pore size and the contrast agent size influence the permeability and perfusion contributions to extravasation. Therefore, DCE-MRI parameters may reflect different physiology with different sensitivity dependent on the contrast agent size [74-76]. Often, BPAs remain intravascular in tumours for several minutes allowing susceptibility MRI as well as DCE-MRI over a longer time scale [77].

\section{Antiangiogenic Treatments}

\subsection{Antibodies and Specialized Proteins}

We have separated the AIs into three subgroups based on their mechanism of action. They are presented in Table 1.

Table 1. Angiogenesis inhibitors.

\begin{tabular}{|c|c|c|c|}
\hline Compound & Angiogenic target & Schedule/dose & References \\
\hline \multicolumn{4}{|c|}{ Antibodies and specialized proteins } \\
\hline Bevacizumab * & VEGF-A $\left(\right.$ VEGF $\left._{165}\right)$ & $1-6 \times 5-45 \mathrm{mg} / \mathrm{kg}$ & {$[78-88]$} \\
\hline DC101 & VEGFR-2 & $7 \times 30 \mathrm{mg} / \mathrm{kg}$ & [89] \\
\hline VEGF-trap & VEGF-A/B, PlGF & $4 \times 25 \mathrm{mg} / \mathrm{kg}$ & {$[90]$} \\
\hline \multicolumn{4}{|c|}{ Tyrosine Kinase Inhibitors } \\
\hline Vatalanib & PDGFR- $\beta$, c-kit, VEGFRs & $7-14 \times 50-100 \mathrm{mg} / \mathrm{kg}$ & {$[91-94]$} \\
\hline Sunitinib & VEGFRs, PDGFRs & $1-7 \times 40-45 \mathrm{mg} / \mathrm{kg}$ & {$[95,96]$} \\
\hline Orantinib & $\begin{array}{l}\text { VEGFR-2, c-kit, FGFR, } \\
\text { PDGFR }\end{array}$ & $1-14 \times 200 \mathrm{mg} / \mathrm{kg}$ & {$[97,98]$} \\
\hline Vandetanib & VEGFR-2, EGFR & $2 \times 12.5-100 \mathrm{mg} / \mathrm{kg}$ & {$[51,99]$} \\
\hline
\end{tabular}


Table 1. Cont.

\begin{tabular}{llcl}
\hline Compound & Angiogenic target & Schedule/dose & References \\
Axitinib & PDGFR, c-kit, VEGFR-1/2/3 & $14 \times 25 \mathrm{mg} / \mathrm{kg}$ & {$[100]$} \\
Imatinib & PDGFR- $\beta$, c-kit, abl, VEGFR-2 $3 \times 50 \mathrm{mg} / \mathrm{kg}$ & {$[101]$} \\
Cediranib & VEGFRs & $1-20 \times 6 \mathrm{mg} / \mathrm{kg}$ & {$[102]$} \\
Sorafenib & VEGFRs, PDGFRs, Raf & $25 \times 7 \mathrm{mg} / \mathrm{kg}$ & {$[103]$} \\
Others & & & \\
TNP-470 & MetAP2 & $3-7 \times 6.7-30 \mathrm{mg} / \mathrm{kg}$ & {$[104]$} \\
Everolimus & mTOR & $1-7 \times 5-10 \mathrm{mg} / \mathrm{kg}$ & {$[105]$} \\
KR-31831 & Unknown & $21 \times 50 \mathrm{mg} / \mathrm{kg}$ & {$[106]$} \\
Thalidomide & FGF-2 & $2-3 \times 60-200 \mathrm{mg} / \mathrm{kg}$ & {$[107-109]$} \\
\hline
\end{tabular}

* and other anti-VEGF antibodies.

The first subgroup comprises monoclonal antibodies and specialized proteins that interfere with the extra-cellular signalling molecules by targeting soluble growth factors or mimicking growth factor receptors.

Among these bevacizumab (and other anti-VEGF antibodies) is by far the most used in the clinic and the best described angiogenesis inhibitor in the literature [17]. In preclinical setups where DCE-MRI is performed to evaluate the anti-vascular effects of bevacizumab, all experiments were performed in immuno-supressed rats (athymic nude). These were bearing either VEGF-expressing human breast cancers [78,79,82,83,85], human glioblastomas [81,84,87], a human ovarian cancer [80], or a small cell lung carcinoma [86]. Treatment dose and schedule varied among experiments as did the imaging schedule (before and from 1 to 30 days after treatment initiation), contrast agent (gadopentetate dimeglumine (Gd-DTPA), Albumin-Gd-DTPA, gadodiamide (Gd-DTPA-BMA), gadoteridol (Gd-HP-DO3A), and gadocoletic acid) and dose of contrast agent ( 0.03 to $0.50 \mathrm{mmol} \mathrm{Gd} / \mathrm{kg}$ ). Despite the many variations in experimental setup all investigations reported a consistent decrease in tumour vascular permeability, as estimated from K(PS) or AUC. A study by Fruth et al. [88] used a mixture of anti-VEGF antibodies to compensate for radiation-induced VEGF-production. Treatment and imaging circumstances were similar to the bevacizumab experiments except the use of mice with a squamous cell carcinoma. DCE-MRI indicated reduced tumour blood volume and hence constrained actions of VEGF. However, they also observed an increase in basic fibroblast growth factor- (bFGF-) production as yet another survival mechanism of the tumour cells.

Another approach at inhibiting the VEGF-VEGFR interaction was taken by Kiessling et al. [89] and Hoff et al. [90] who used DC101 and VEGF-trap, respectively. Although very different setups were used the consensus was still a decrease in tumour vascularization defined by DCE-MRI parameters.

The majority of experiments in this subgroup were validated using histology to assess vascular morphology, vessel density or cell viability/necrosis.

\subsection{Tyrosine Kinase Inhibitors}

The second major subgroup of angiogenesis inhibitors are the Tyrosine Kinase Inhibitors (TKIs). These can specifically inhibit the phosphorylation of tyrosines and hence interrupt the downstream signalling cascade of activated growth factor receptors. This inhibition is achieved by either competing 
with adenosine triphosphate (ATP), competing with the substrate protein that is to be phosphorylated, or by conformational change leading to allosteric inhibition. The majority of TKIs are based on competitive binding in or around the active ATP-binding site of the tyrosine kinases. Most TKIs target the VEGF signalling pathway, and many TKIs target multiple growth factor receptors, leading to multiple shut down of signalling pathways.

Vatalanib (PTK787/ZK222584) is the most investigated drug in preclinical setups using DCE-MRI to evaluate anti-angiogenic effects. Both mice and rats have been used for in vivo models to test vatalanibs effect on a range of tumour xenografts/cell lines (human breast cancer [91], melanoma cells [92], glioma cells [93], and renal cell carcinoma [94]). The treatment dose and schedule for these experiments are somewhat similar (table), and the same can be said about the use of contrast agents (gadoterate meglumine (Gd-DOTA) or albumin-Gd-DTPA) and imaging schedules (imaged before and after last treatment). In three of four tumour models a decrease in vascular permeability was observed as estimated from $K^{\text {trans }}$ and K(PS). The only exception was the glioma model that showed an increase in $K^{\text {trans }}$ in the tumour periphery. This difference could be explained by the lack of tumour segmentation when analysing the DCE-MRI data. In the three studies that showed a decrease in permeability the tumour ROI was not segmented, whereas the fourth study had divided the tumour into a core and a rim region. The lack of segmentation could hence camouflage a local peripheral increase in permeability, and explain the observed differences. Ali et al. [93] found that the increase in permeability of the tumour rim was attributed to vasodilation due to VEGF expression.

Sunitinib (SU11248) was tested in mice bearing either a human colon carcinoma [95] or a pancreatic carcinoma [96]. Both experiments showed a decrease in $K^{\text {trans }}$ although contrast agents (albumin-Gd-DTPA and P846), treatment schedules and hence imaging schedules were different.

In two very similar experiments [97,98] treatment with orantinib (SU6668) in mice bearing a human colon carcinoma revealed an enhancement in the tumour periphery after 3 days of treatment. This was however preceded by a decrease in permeability of both tumour rim and periphery $24 \mathrm{~h}$ after treatment. These observations indicated that prolonged treatment facilitates vascularization/ vasodilation/permeabilization in the tumour periphery possibly due to increased expression of VEGF. This phenomenon was also observed in a study using vatalanib [93].

Vandetanib (ZD6474) and its less soluble predecessor ZD4190 were evaluated in mice bearing a human prostate cancer. Both studies used same treatment schedule and dose as well as imaging schedules. The only differences were the use of contrast agent, which was either a small agent [99] or a macromolecular agent [51], or the model used to analyse DCE-MRI data (de Bazelaire vs. Tofts). Vandetanib showed a dose-dependent decrease in $K^{\text {trans }}$, which could be due to both perfusion and permeability as this study used the small contrast agent, and ZD4190 showed a reduction of tumour vascular permeability, vascular volume and blood flow. Both studies showed similar effects of anti-angiogenic treatment, but one should keep in mind that the size of contrast agent has major influence on the interpretation of the results. Macromolecular contrast agents are more likely to report permeability than perfusion, and vice versa for small contrast agents, but it will always be a combined measurement of the two parameters.

Axitinib (AG013736) [100], imatinib (STI571) [101], and cediranib (AZD2171) [102] were only used in one study each, involving mice bearing either a human breast cancer (axitinib), a human prostate 
cancer (imatinib), or different glioblastomas (cediranib). All studies used similar imaging schedules and contrast agents and showed a decrease in vascular permeability estimated either by $K^{\text {trans }}$ or K(PS).

Last study in this subgroup involved sorafenib [103] treatment in rats bearing a human breast cancer. Reduced tumour blood flow and vascular permeability was achieved in this study as well.

To summarize, most TKIs induce a decrease in vascular permeability and perfusion, but interpretation should be done with caution as tumour segmentation, use of contrast agent, and prolonged treatment has an influence on the acquired DCE-MRI data. Indeed, this was addressed in the majority of studies in this subgroup as obtained results with DCE-MRI were supported by relevant histology.

\subsection{Other Mechanisms of Action}

This subgroup comprises drugs that exert their anti-angiogenic effect by targeting the endothelium (TNP-470 (AGM-1470)) [104], suppressing the immune system (everolimus (RAD001)) [105] or whose mechanism of action has not yet been clearly defined (KR-31831) [106].

TNP-470 is a fumagilin-analogue (antibiotic) that targets and irreversibly inactivates methionine aminopeptidase-2 (MetAP2) in endothelial cells. This results in inhibition of endothelial cell proliferation and migration, and hence tumour angiogenesis. This study used mice bearing a rat prostate cancer that were treated for approximately a week and imaged using a macromolecular contrast agent before and after the last treatment. This study observed a decrease in tumour vascular volume, as well as local increases and decreases in permeability.

Everolimus is an immuno-suppressant that, when in complex with the immunophilin FK binding protein-12 (FKBP-12), binds to and inhibits the mammalian target of rapamycin (mTOR). Evidence suggests that mTOR is an important signalling molecule in the activation of tumour angiogenesis [110]. In this study mice bearing B16/BL6 melanoma lymph node metastasis and rats bearing BN472 mammary tumours were imaged with both small and macromolecular contrast agents before and after treatment. Despite an observed anti-tumour effect of everolimus, no significant difference was observed in any of the DCE-MRI parameters, except a reduced Ve in mice bearing B16/BL6. Authors attributed this to the devastating effect of everolimus on both pericytes and endothelial cells. By destroying the covering pericytes, vascular leakage would still be in effect and give no change or even increase the $K^{\text {trans }}$ parameter.

The drug KR-31831 has been reported to suppress endothelial cell proliferation, tube formation, invasion, and migration in vitro as well as vessel formation in vivo [106]. The mechanism of its anti-angiogenic actions remains unclear but is indicated to interfere with the VEGF signalling pathway. In this study mice bearing a human ovarian carcinoma were imaged using a small contrast agent and a decrease in $K^{\text {trans }}$ was observed from day 0 to day 21 in treated animals. No difference in $K^{\text {trans }}$ was observed in controls.

Thalidomide has been investigated in different scenarios [107-109]. One study found reduced vessel permeability for a macromolecular contrast agent as a result of vascular normalization [108], while another study found increased blood plasma volume fraction [107].

As this subgroup contains drugs that have different mechanisms of action it is not surprising to find that they behave differently when analysed with DCE-MRI. Another lesson to take from these studies is 
that if a drug has multiple or unknown effector functions these can counteract or influence each other giving unexpected results when DCE-MRI parameters are estimated.

\section{Vascular Disrupting Agents}

\subsection{Tubulin Binding Agents}

We have separated the VDAs into three subgroups based on their mechanism of action. They are presented in Table 2 .

Table 2. Vascular disrupting agents.

\begin{tabular}{|c|c|c|c|}
\hline Compounds & Dose/schedule & DCE-MRI & References \\
\hline \multicolumn{4}{|l|}{ Tubulin binding } \\
\hline \multirow[t]{2}{*}{ CA4P } & $1-2 \times 10-250 \mathrm{mg} / \mathrm{kg}$ (mouse) & $1-24 \mathrm{~h}$ & {$[77,111-121]$} \\
\hline & $1 \times 10-100 \mathrm{mg} / \mathrm{kg}(\mathrm{rat})$ & $1 \mathrm{~h}-9$ days & {$[70,122-125]$} \\
\hline OXi4503 & $1-2 \times 25-100 \mathrm{mg} / \mathrm{kg}$ (mouse) & $4-144 \mathrm{~h}$ & {$[114]$} \\
\hline \multirow[t]{2}{*}{ ZD6126 } & $1 \times 50-200 \mathrm{mg} / \mathrm{kg}$ (mouse) & $24 \mathrm{~h}$ & {$[126,127]$} \\
\hline & $1 \times 2.5-50 \mathrm{mg} / \mathrm{kg}(\mathrm{rat})$ & $1-120 \mathrm{~h}$ & {$[125,128-131]$} \\
\hline NPI2358 & $1 \times 2.5-15 \mathrm{mg} / \mathrm{kg}$ (mouse) & $1-24 \mathrm{~h}$ & {$[132]$} \\
\hline Stilbene $5 \mathrm{c}$ and $6 \mathrm{c}$ & $1 \times 50 \mathrm{mg} / \mathrm{kg}$ (mouse) & $4 \mathrm{~h}$ & [133] \\
\hline TZT-1027 & $1 \times 0.5 \mathrm{mg} / \mathrm{kg}(\mathrm{rat})$ & $1-3 \mathrm{~h}$ & [134] \\
\hline ABT-751 & $1 \times 30 \mathrm{mg} / \mathrm{kg}$ (rat) & $1-6 \mathrm{~h}$ & [135] \\
\hline \multicolumn{4}{|l|}{ TNF- $\alpha$ inducing } \\
\hline \multirow[t]{2}{*}{ DMXAA } & $1-4 \times 22-30 \mathrm{mg} / \mathrm{kg}$ (mouse) & $3-24 \mathrm{~h}$ & {$[113,136-143]$} \\
\hline & $1 \times 100-350 \mathrm{mg} / \mathrm{kg}$ (rat) & $4-24 \mathrm{~h}$ & {$[144]$} \\
\hline TNF- $\alpha$ & $\begin{array}{l}300 \mu \mathrm{g} / \mathrm{kg} \text { or viral } \\
\text { overexpression (mouse) }\end{array}$ & $2-96 \mathrm{~h}$ or 3 days & {$[145,146]$} \\
\hline $\mathrm{AP} / 1649, \mathrm{AP} / 1897$ & $4 \times 27 \mathrm{mg} / \mathrm{kg}$ (mouse) & $3-24 \mathrm{~h}$ & {$[143]$} \\
\hline \multicolumn{4}{|l|}{ Other } \\
\hline \multirow[t]{2}{*}{ Radiation } & $\begin{array}{l}8-18 \text { Gy single dose or } \\
\text { fractionated (rat) }\end{array}$ & $2-25$ days & {$[147,148]$} \\
\hline & $\begin{array}{l}20 \text { Gy single dose or fractionated } \\
\text { (mouse) }\end{array}$ & $3-120 \mathrm{~h}$ & {$[32]$} \\
\hline \multicolumn{4}{|l|}{ Photosensitizers } \\
\hline Bacteriochlorophyll-serine & $1 \times 20 \mathrm{mg} / \mathrm{kg}$ (mouse) & $1-24 \mathrm{~h}$ & {$[136,149]$} \\
\hline \multicolumn{4}{|l|}{ Targeted chemotherapy } \\
\hline MBT-0206 & $3 \times 5 \mathrm{mg} / \mathrm{kg}$ (hamster) & $24 \mathrm{~h}$ & {$[150]$} \\
\hline EndoTAG $^{\circledR}-2$ & $6 \times 2.5 \mathrm{mg} / \mathrm{kg}$ (mouse) & $24 \mathrm{~h}$ & {$[151]$} \\
\hline
\end{tabular}

For a recent review of clinical studies and DCE-MRI considerations, see [152]. Tubulin binding agents depolymerises tubulin or inhibits polymerization of tubulin to microtubules, which are part of the cytoskeleton maintaining the shape of endothelial cells. The induced changes in endothelial morphology cause vascular shut-down within a few hours and induce necrosis detectable at $24 \mathrm{~h}$. The tubulin binding agents include combretastatins, which are natural stilbenoid natural phenols isolated from South African Bush Willow Combretum caffrum. Studies include the derivatives combretastatin A-4 phosphate 
(CA4P) and combretastatin A-1 Phosphate (OXi4503 (CA1P)). ZD6126 is a prodrug of $N$-acetylcolchinol, related to colchicines. NPI2358 (plinabulin) has been derived from a marine microbial source. It binds to the colchicine binding site of b-tubulin preventing polymerization and disrupting the cytoplasmic microtubule network. Other agents are stilbene 5c and 6c, TZT-1027 (soblidotin), and ABT-751. The different effect of CA4P, OXi4503, and NPI2358 in the C3H mammary carcinoma is shown in Figure 1. IAUC and $K^{\text {trans }}$ from concentration time curves and Toft's model showed the same effect.

Figure 1. Effect of combretastatin A-4 phosphate (CA4P) (25 mg/kg) [117], NPI (7.5 mg/kg) [132], and combretastatin A-1 Phosphate (OXi4503) (50 mg/kg) (unpublished data) in $200 \mathrm{~mm}^{3} \mathrm{C} 3 \mathrm{H}$ mammary carcinomas as measured by initial area under the curve (IAUC) $(90 \mathrm{~s})$ (red) and $K^{\text {trans }}$ from Toft's model (blue) $3 \mathrm{~h}$ following treatment. Bars show mean of tumour median values $\pm \mathrm{SE}$.

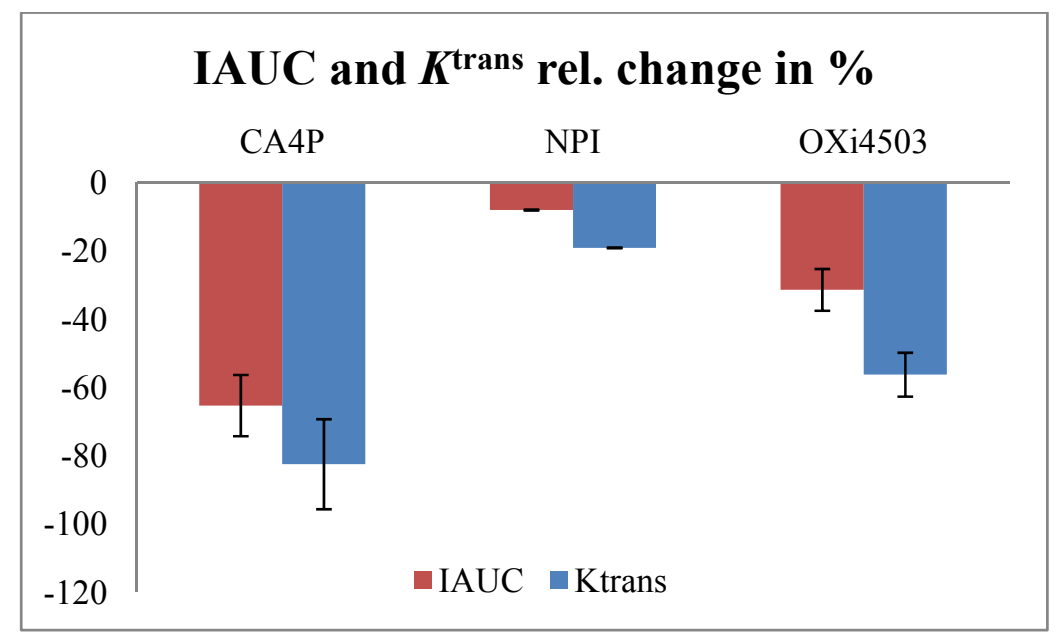

DCE-MRI studies of CA4P has been done in the rat tumour models P22 carcinosarcoma[70,122], 13762NF mammary carcinoma[123], and R1 liver rhabdomyosarcoma[124,125], and in the murine tumour models sarcoma F [111], RIF-1 fibrosarcoma [112], SaS sarcoma [112], SaF sarcoma [112], C3H mammary carcinoma [77,112,117,119,120], KHT sarcoma [114,116,119,120], and EL4 lymphoma [121]. In immunodeficient mice, the following human tumour models were investigated; the colon adenocarcinomas HT29 [112,113], LoVo [112], LS174T [113], and SW1222 [115], and the mammary carcinoma MDA-MB-231 [118]. The CA4P doses investigated were single injections in the dose range $10-100 \mathrm{mg} / \mathrm{kg}$ in rats, and single or two injections of $10-250 \mathrm{mg} / \mathrm{kg}$ in mice. Imaging schedules varied with DCE-MRI examinations before and from 1-144 h following treatment, and the contrast agents included gadopentetate dimeglumine $(0.1-0.3 \mathrm{mmol} / \mathrm{kg})$, gadodiamide $(0.04-0.2 \mathrm{mmol} / \mathrm{kg})$, gadoterate meglumine $(0.2 \mathrm{mmol} / \mathrm{kg})$, and feruglose (NC100150) $(2.5 \mathrm{mg} \mathrm{Fe} / \mathrm{kg})$. The effect of a single CA4P dose $(100 \mathrm{mg} / \mathrm{kg})$ on IAUC in 4 different tumour models is shown in Figure 2. 
Figure 2. Effect of CA4P (100 mg/kg) as measured by IAUC (90 or $94 \mathrm{~s}$ from concentration time curves) following injection of gadopentetate dimeglumine $(0.1 \mathrm{mmol} / \mathrm{kg})$ in 4 tumour models: C3H mammary carcinoma [117], KHT sarcoma [117], P22 carcinosarcoma [70], and SW1222 human colonic adenocarcinoma [115]. Bars show mean of tumour mean or median values $\pm \mathrm{SE}$.

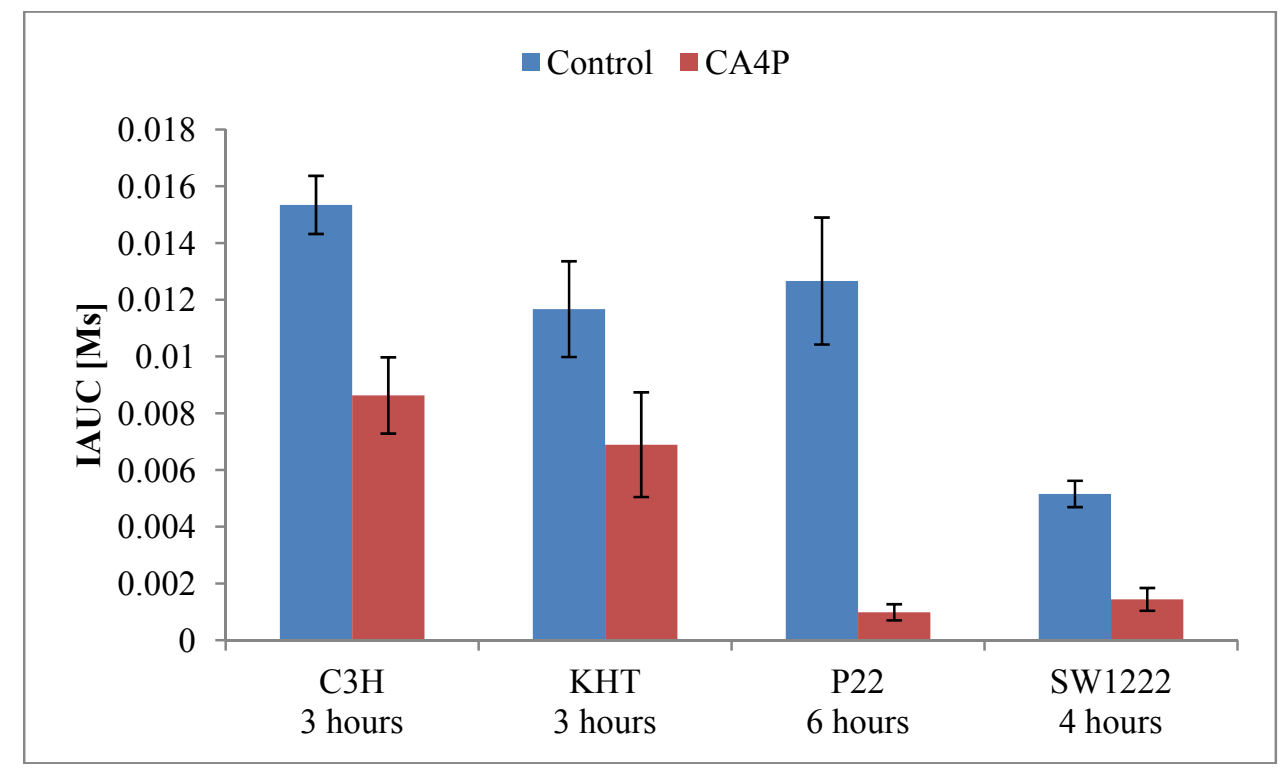

In general, the studies show reduction in perfusion and permeability $1-6 \mathrm{~h}$ after treatment. Changes in IAUC and $K^{\text {trans }}$ tended to be smaller than measured by radiolabelled IAP, but have shown similar dose-response and time course [70,122]. Some studies found dependency on tumour model [112,113,119]. Beauregard et al. [112,113] found that decrease in energy status by ${ }^{31} \mathrm{P}$ nuclear magnetic resonance (NMR) spectroscopy corresponded well with DCE-MRI changes in a range of tumour models. Zhao et al. found consistent results from DCE-MRI and bioluminescence imaging [118]. Often, histology has been used to assess necrosis, which is typically seen in the tumour centre from $24 \mathrm{~h}$ after treatment. Also histology involving vascular staining and the functional perfusion marker Hoechst 33342 was often used to support the DCE-MRI data. Perfusion recovery was seen in the periphery or whole tumour from $24 \mathrm{~h}$ to 9 days [114,115,121,123-125]. Recovery in the tumour rim while central perfusion remained low has been correlated with oxygen levels by ${ }^{19} \mathrm{~F}$ oximetry [123]. One study in the KHT sarcoma compared CA4P and the other combretastatin derivative OXi4503 showing a slower perfusion recovery after OXi4503 treatment [114]. A dose response of CA4P in the C3H mammary carcinoma was similar in shape to a dose response of CA4P in combination with radiotherapy as estimated by $\mathrm{TCD}_{50}$ indicating that the vascular effects $3 \mathrm{~h}$ after treatment reflect the drug's impact on radiotherapy [117]. An optimal dose was found at $25 \mathrm{mg} / \mathrm{kg}$, and the doses were converted to milligram per square millimeter surface for comparison with a clinical study. At this optimal dose, $K^{\text {trans }}$ from the Toft's model was reduced by $83 \%$, but if the model was extended to estimate blood plasma volume $v_{\mathrm{p}}$, $K^{\text {trans }}$ was reduced by $47 \%$ and $v_{\mathrm{p}}$ by $81 \%$ indicating that blood volume change was a part of the response. Figure 3 shows that $K^{\text {trans }}$ was lower when $v_{\mathrm{p}}$ was estimated rather than assumed negligible. 
Figure 3. Parametric maps of IAUC (90 s) and parameters from Toft's model excluding (upper) and including (lower) blood volume fraction $v_{\mathrm{p}}$ in a $200 \mathrm{~mm}^{3} \mathrm{C} 3 \mathrm{H}$ mammary carcinoma.
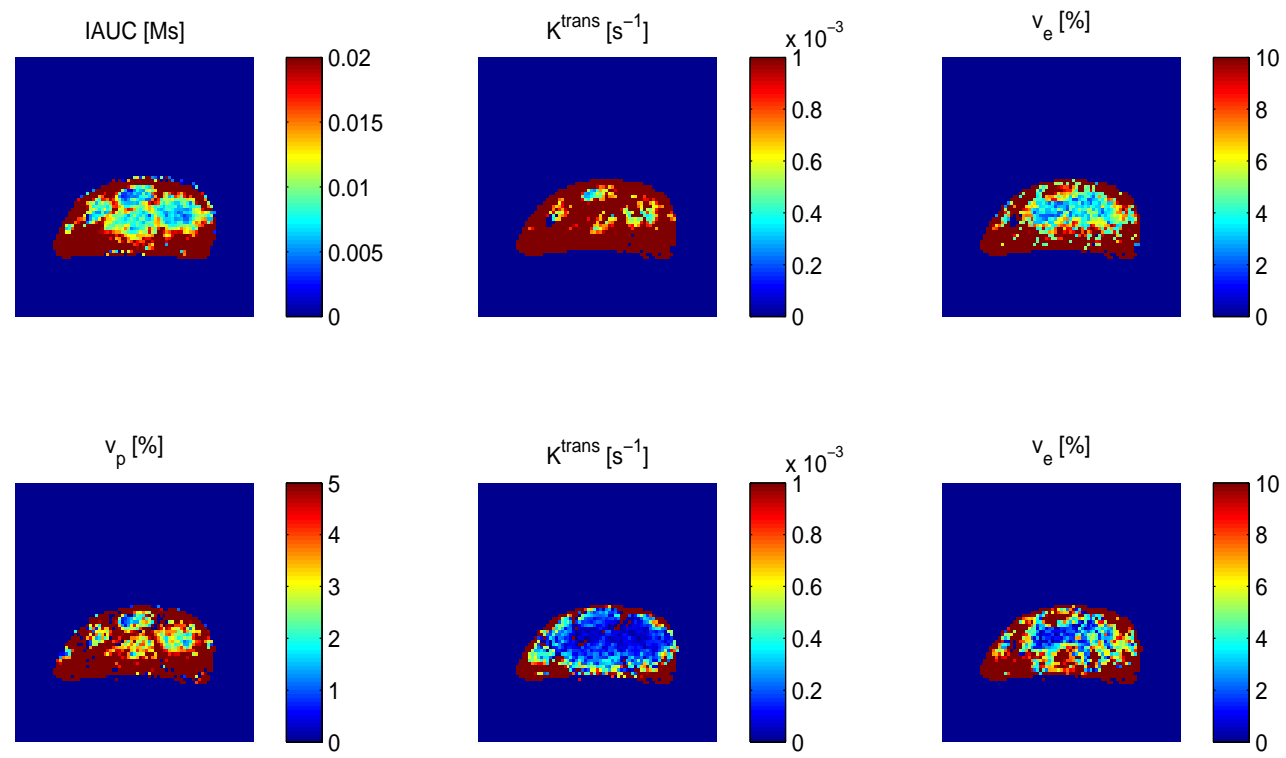

ZD6126 has been investigated in the rat tumour models GH3 prolactinoma $[128,129]$ and R1 rhabdomyosarcoma [125,131], and the Hras5 transformed NIH 3T3 fibroblast in athymic rats [130]. The C38 colon adenocarcinoma was investigated in mice [126], and a study on the DU-145 human prostate cancer was done in severe combined immunodeficient (SCID) mice [127]. In rats, doses between $2.5-50 \mathrm{mg} / \mathrm{kg}$ were given, and in mice doses varied from $50-200 \mathrm{mg} / \mathrm{kg}$. DCE-MRI was performed before and 1-120 h following single drug injections, and the contrast agents used were gadopentetate dimeglumine $(0.3 \mathrm{mmol} / \mathrm{kg})$, gadodiamide $(0.1 \mathrm{mmol} / \mathrm{kg})$, gadoterate meglumine $(0.02 \mathrm{mmol} / \mathrm{kg})$, and albumin-Gd-DTPA (500 mg/kg). The studies show vascular shutdown in a dose-dependent manner with slightly different time courses seen in the rat studies, which may depend on drug dose and tumour type. Using low-molecular weight contrast agents (gadodiamide and gadoterate meglumine), Wang et al. found $K^{\text {trans }}$ to be decreased at $1 \mathrm{~h}$ with recovery starting from $6 \mathrm{~h}$ (dose $10 \mathrm{mg} / \mathrm{kg}$ ) [125] or $48 \mathrm{~h}$ (dose $20 \mathrm{mg} / \mathrm{kg}$ ) [131] in the R1 rhabdomyosarcoma, and McIntyre et al. found no signs of recovery up to $96 \mathrm{~h}$ after treatment with the dose $50 \mathrm{mg} / \mathrm{kg}$ in the $\mathrm{GH} 3$ prolactinoma [129].

NPI2358 given at doses ranging from 2.5 to $15 \mathrm{mg} / \mathrm{kg}$ was tested by DCE-MRI with gadopentetate dimeglumine in the mouse $\mathrm{C} 3 \mathrm{H}$ mammary carcinoma [132]. At a dose of $7.5 \mathrm{mg} / \mathrm{kg}$, NPI2358 reduced IAUC and $K^{\text {trans }}$ after $1 \mathrm{~h}$, peaked at $3 \mathrm{~h}$ and returned to normal after $24 \mathrm{~h}$. When extending Toft's model to estimate $v_{\mathrm{p}}, v_{\mathrm{p}}$ was more likely to change significantly than $K^{\text {trans }}$ indicating that blood volume change was a part of the response.

Stilbene $5 \mathrm{c}$ and $6 \mathrm{c}$ are also microtubule inhibitors binding at the colchicine binding site. They have been tested in the human ovarian cell cancer line UCI-101/luciferase at a single dose of $50 \mathrm{mg} / \mathrm{kg}$ [133]. DCE-MRI with $50 \mu \mathrm{L}$ gadodiamide showed selective suppression of tumour perfusion without damaging normal organ perfusion. 
TZT-1027 is another tubulin inhibitor with cytotoxic properties used in chemotherapy. Its antivascular properties at a single dose of $0.5 \mathrm{mg} / \mathrm{kg}$ has been tested by DCE-MRI with gadopentetate dimeglumine $(0.2 \mathrm{mmol} / \mathrm{kg})$ in the human breast tumour MX-1 (grown in mouse) and DiMethylBenz(a)Anthracene induced breast tumours (grown in rats) showing reduced blood flow 1-3 $\mathrm{h}$ after treatment in both tumour types [134].

The novel tubulin-binding agent ABT-751 has been investigated by DCE-MRI using gadopentetate dimeglumine $(0.2 \mathrm{mmol} / \mathrm{kg})$ in the $9 \mathrm{~L}$ glioma in rats [135]. A single injection at the dose $30 \mathrm{mg} / \mathrm{kg}$ resulted in reduced tumour perfusion after $1 \mathrm{~h}$ and restoration of perfusion after $6 \mathrm{~h}$. Perfusion was estimated as the maximum slope of signal intensity curves, and the effect was seen in all of 3 tumour regions defined by their distance to the tumour edge.

\subsection{TNF- $\alpha$ Inducing Agents}

The tumour necrosis factor- $\alpha$ (TNF- $\alpha$ ) inducing drug DMXAA (Vadimezan, ASA404) has been investigated by DCE-MRI in the rat GH3 prolactinoma [144], in a range of murine tumours including MCA205 (methylcholantrene-induced fibrosarcoma) [139] and SaF sarcoma [143], and in a number of human xenografts in mice including HT29 and LS174T colon adenocarcinomas [113], FaDu [137,141,142], A253 [137], and patient-derived [142] head and neck carcinomas. Seshadri et al. used different Gd-based macromolecular contrast agents to assess blood volume and permeability [137,139,141,142]. Additional MRI studies by this group assess extravasation and accumulation of macromolecular contrast agent at a longer time scale, 4 and $24 \mathrm{~h}$, in the murine Colon-26 colon carcinoma [136] and CT-26 colon adenocarcinoma [138], and in the human U87 glioma [140]. In rats, doses in the range $100-350 \mathrm{mg} / \mathrm{kg}$ were used, and in mice doses varied between 22-30 mg/kg. DCE-MRI was scheduled before treatment or in control animals, and from 3-24 h after treatment using the contrast agents gadopentetate dimeglumine $(0.2 \mathrm{mmol} / \mathrm{kg})$, gadodiamide $(0.1 \mathrm{mmol} / \mathrm{kg})$, gadofosveset (Gd-DTPA derivative) $(0.1 \mathrm{mmol} / \mathrm{kg})$, albumin-Gd-DTPA $(0.1 \mathrm{mmol} / \mathrm{kg})$, poly-lysine-Gd-DTPA $(0.1 \mathrm{mmol} / \mathrm{kg})$, or methoxy-PEG succinyl-poly-L-lysine-GdDTPA $(0.1 \mathrm{mmol} / \mathrm{kg})$. The main findings are vascular disruption $24 \mathrm{~h}$ following treatment seen with decreased IAUC or $K^{\text {trans }}$. Increased permeability $4 \mathrm{~h}$ after treatment followed by decreased permeability $24 \mathrm{~h}$ after treatment has been observed in two studies [136,138]. Also marked extravasation and accumulation of albumin-Gd-DTPA $24 \mathrm{~h}$ following treatment indicated vascular disruption [140]. In the rat GH3 prolactinoma [144], an effect was only seen with the large dose of $350 \mathrm{mg} / \mathrm{kg}$.

In the study of Barbera et al. [143], the DMXAA analogues AP/1649 and AP/1897 showed no antivascular effect in the SaF sarcoma as seen by DMXAA. Single injection of TNF- $\alpha$ at a dose of $300 \mu \mathrm{g} / \mathrm{kg}$ in the MC38 murine colon adenocarcinoma showed reduced vascular parameters from $2-96 \mathrm{~h}$ following treatment. Tumours infected with Ad.EGR-TNF respond to radiation with induction of TNF- $\alpha$ expression, and this was investigated in the PC-3 human prostate cancer grown in athymic mice [146]. DCE-MRI and electron paramagnetic resonance imaging (EPRI) suggested reduced perfusion and oxygenation 3 days after treatment. 


\subsection{Other Vascular Disrupting Treatments}

The antivascular effects of radiotherapy have been investigated by DCE-MRI in a few studies [32,147,148]. In the MAT-LyLu tumour (subline of the Dunning R3327 rat prostate adenocarcinoma), Kiessling et al. [147] found the irradiation slowed tumour growth, but no change in the DCE-MRI parameter Kep from the Hoffman model using gadopentetate dimeglumine $(0.2 \mathrm{mmol} / \mathrm{kg})$. The lack of difference could be explained by the rapid regeneration of the MAT-LyLu tumour subtype. De Kayser et al. 1090 [148] compared single dose 8 Gy with $5 \times 3$ Gy in the R1 rhabdomyosarcoma. Single dose radiation showed perfusion decrease 2 days after treatment, with a slow recuperation. Fractionated radiation showed similar perfusion decrease early after treatment. Horsman et al. [32] also compared single dose vs. fractionated irradiation in the $\mathrm{C} 3 \mathrm{H}$ mouse mammary carcinoma. A large single dose was superior to the same dose given in a more conventional fractionated schedule, but vascular-mediated effects did not account for this.

Photosensitizers also have vascular disrupting properties. Zilberstein et al. [149] found that a single injection of bacteriochlorophyll-serine at the dose $20 \mathrm{mg} / \mathrm{kg}$ in a study of the M2R melanoma xenograft in mice caused severe reduction in tumour perfusion $24 \mathrm{~h}$ after treatment. Seshadri et al. [136] found that photodynamic treatment with 2-[1-hexyloxyethyl]-2-devinyl pyropheophorbide-a (HPPH) $(0.4 \mu \mathrm{mol} / \mathrm{kg})$ or 5-aminolevulinic acid (ALA) $(6 \times 20 \mu \mathrm{L})$ produced subtle vascular injury below the threshold needed to achieve the catastrophic vascular collapse and dissolution. Combination of PDT and DMXAA provided therapeutically synergistic and selective antitumor activity.

Chemotherapy targeted against the vasculature has been investigated by Eichhorn et al. [150,151]. Paclitaxel, a tubulin stabilizer, encapsulated in cationic lipid complexes (MBT-0206) was administered at an effective dose of $5 \mathrm{mg} / \mathrm{kg}$ daily for 3 days in the amelanotic hamster melanoma A-MEL-3 [150]. 24 $\mathrm{h}$ after last treatment, a decrease in intratumoural blood volume and increase in vascular permeability were seen. The topoisomerase I inhibitor camptothecin in cationic lipid complexes (EndoTAG-2) administered at the effective chemotherapy dose $2.5 \mathrm{mg} / \mathrm{kg}$ on days $7,9,11,14,16$, and 18 after inoculation of the Lewis Lung Carcinoma LLC-1 in mice also gave significant reduction in tumour vascular volume and tumour perfusion [151].

\section{Conclusions and Future Perspectives}

DCE-MRI is a useful tool to assess in vivo drug effects on vasculature. The term DCE-MRI covers methods with different imaging sequences, analysis of either (relative) image signal time curves or concentration time curves with different descriptive or model based parameters. The parameters are furthermore influenced by the choice of contrast agent. While this amount of possibilities makes it possible to tailor DCE-MRI methods to individual studies, it makes study comparison challenging. One needs to have the actual method in mind when reading a published study. Attempts have been done to standardize methods and nomenclature [54,64], and especially in clinical trials standardization is important. Preclinical studies should be comparable as well, but they also benefit from a larger arsenal of contrast agents, magnet field strengths, and additional imaging and histological methods. In this review, we have to a large degree maintained the individual papers' terminology and interpretation and at some places commented on relevant method details. 
A general and returning issue is the dependence of $K^{\text {trans }}$ and other extravasation-describing parameters on both perfusion and permeability. Reduced perfusion occurring simultaneously with increased permeability surface area product as a result of vascular targeting will influence extravasation in opposite ways. The extravasation-describing parameter would in this case provide little and hardly interpretable information on the microvascular situation. As stated in the introduction, separation of these properties is not trivial and part of the standard models. Another influence on $K^{\text {trans }}$ is blood volume when an invalid assumption of negligible blood volume fraction is made. The initial fast increase in concentration time curves arising from the filling of blood vessels will in this case be attributed to extravasation instead of blood volume. Figure 3 shows an example of difference in $K^{\text {trans }}$ when comparing Toft's model analysis without and with inclusion of a vascular term (Equations 1 and 2). This illustrates the effect seen in [117] where the CA4P effect on $K^{\text {trans }}$ was lower when $v_{\mathrm{p}}$ was estimated.

DCE-MRI analysis is sometimes made in ROIs covering whole or part of the tumour, but very often the analysis is made voxel-wise. In studies with voxel-wise analysis, a single value such as median or mean is often used for statistics. The median can be chosen to avoid heavy influence on the mean value from single outlier estimates from e.g. poor curve fits. Preclinical studies are often performed at higher magnetic field strengths allowing higher spatial resolution. This could provide insight into partial-volume effects at clinical field strengths. In voxel-wise analyses, the spatial information can be described statistically, and a tumour's voxels can be segmented into groups. Tumours lack anatomical fix points, and segmentation can be done by different principles. Some involve spatial knowledge, e.g., that VTAs often show different effects in the tumour centre $v$. the tumour rim. A ROI can be drawn manually, by morphological image operations segmenting e.g., the tumour rim, or by region growing to expand a chosen area to include voxels with similar properties. Other segmentation methods assume no spatial knowledge, e.g., histogram thresholding or multivariate clustering. We have attempted to investigate the effect of CA4P in $\mathrm{C} 3 \mathrm{H}$ mammary carcinomas segmented into three regions with similar characteristics based on the three parameters estimated from the extended Toft's model [119]. The method did not take into account the voxels' spatial location, but the identified regions tended to be connected rather than scattered. Segmentation may provide more information from DCE-MRI data, but the many approaches make study comparison even more difficult.

DCE-MRI is an important method for assessing the effect of antivascular treatments in preclinical studies. The imaging protocol and analysis involve many choices that can optimize the individual studies but make study comparison harder. A consensus model has been proposed to overcome this, but other models are still relevant. Future perspectives involve more complicated models separating perfusion and permeability, and also improved use of spatial image information.

\section{Acknowledgements}

Grant support for authors: The Danish Cancer Society; the Danish Council for Independent Research: Medical Sciences; the Danish Programme Commission on Strategic Growth Technologies (NaBIIT) grant nr. 2106-05-0031; CIRRO-The Lundbeck Foundation Center for Interventional Research in Radiation Oncology and The Danish Council for Strategic Research; Erland Richard Frederiksen og Hustrus Legat (fond); and Andersen-Isted Fonden. 


\section{Conflict of Interest}

Michael R. Horsman is consultant for OXiGENE.

\section{References}

1. Brem, S.; Brem, H.; Folkman, J.; Finkelstein, D.; Patz, A. Prolonged tumor dormancy by prevention of neovascularization in the vitreous. Cancer Res. 1976, 8, 2807-2812.

2. Folkman, J. How is blood vessel growth regulated in normal and neoplastic tissue? G.H.A. Clowes memorial Award lecture. Cancer Res. 1986, 2, 467-473.

3. Hahnfeldt, P.; Panigrahy, D.; Folkman, J.; Hlatky, L. Tumor development under angiogenic signaling: A dynamical theory of tumor growth, treatment response, and postvascular dormancy. Cancer Res. 1999, 19, 4770-4775.

4. Bergers, G.; Benjamin, L.E. Tumorigenesis and the angiogenic switch. Nat. Rev. Cancer. 2003, 6, $401-410$.

5. Vaupel, P.; Kallinowski, F.; Okunieff, P. Blood flow, oxygen and nutrient supply, and metabolic microenvironment of human tumors: A review. Cancer Res. 1989, 23, 6449-6465.

6. Stoeltzing, O.; Ellis, L.M. The role of microvasculature in metastasis formation. In Vascular-Targeted Therapies in Oncology; Siemann, D.W., Ed.; John Wiley \& Sons, Ltd.: Chichester, UK, 2006; pp. 31-62.

7. Vaupel, P. Tumor microenvironmental physiology and its implications for radiation oncology. Semin. Radiat. Oncol. 2004, 3, 198-206.

8. Harris, A.L. Hypoxia-A key regulatory factor in tumour growth. Nat. Rev. Cancer. 2002, 1, $38-47$.

9. Siemann, D.W.; Bibby, M.C.; Dark, G.G.; Dicker, A.P.; Eskens, F.A.L.M.; Horsman, M.R.; Marmé, D.; Lorusso, P.M. Differentiation and definition of vascular-targeted therapies. Clin. Cancer Res. 2005, 2, 416-420.

10. Horsman, M.R.; Siemann, D.W. Pathophysiologic effects of vascular-targeting agents and the implications for combination with conventional therapies. Cancer Res. 2006, 24, 11520-11539.

11. Ferrara, N.; Gerber, H.P.; Le Couter, J. The biology of VEGF and its receptors. Nat. Med. 2003, 6, 669-676.

12. Pugh, C.W.; Ratcliffe, P.J. Regulation of angiogenesis by hypoxia: role of the HIF system. Nat. Med. 2003, 6, 677-684.

13. Kerbel, R.; Folkman, J. Clinical translation of angiogenesis inhibitors. Nat Rev Cancer 2002, 10, 727-739.

14. Marme, D. The impact of anti-angiogenic agents on cancer therapy. J. Cancer Res. Clin. Oncol. 2003, 11, 607-620.

15. Eskens, F.A. Angiogenesis inhibitors in clinical development; Where are we now and where are we going? Br. J. Cancer 2004, 1, 1-7.

16. Ferrara, N.; Kerbel, R.S. Angiogenesis as a therapeutic target. Nature 2005, 7070, 967-974.

17. Heath, V.L.; Bicknell, R. Anticancer strategies involving the vasculature. Nat. Rev. Clin. Oncol. 2009, 7, 395-404. 
18. National Cancer Institute. Available online: www.cancer.gov/clinicaltrials (accessed on 1 May 2012).

19. Horsman, M.R.; Overgaard, J. Thermal radiosensitization in animal tumors: the potential for therapeutic gain. In Hyperthermia and Oncology; Urano, M., Douple, E., Eds.; VSP: Utrecht, The Netherland, 1985; Vol. 2, pp. 113-145.

20. Chaplin, D.J.; Dougherty, G.J. Tumour vasculature as a target for cancer therapy. Br. J. Cancer 1999, 80, 57-64.

21. Thorpe, P.E. Vascular targeting agents as cancer therapeutics. Clin. Cancer Res. 2004, 2, 415-427.

22. Siemann, D.W.; Chaplin, D.J.; Horsman, M.R. Vascular-targeting therapies for treatment of malignant disease. Cancer 2004, 12, 2491-2499.

23. Baguley, B.C. Antivascular therapy of cancer: DMXAA. Lancet Oncol. 2003, 3, 141-148.

24. Tozer, G.M.; Kanthou, C.; Baguley, B.C. Disrupting tumour blood vessels. Nat. Rev. Cancer 2005, $6,423-435$.

25. Weidner, N.; Semple, J.P.; Welch, W.R.; Folkman, J. Tumor angiogenesis and metastasis - Correlation in invasive breast carcinoma. N. Engl. J. Med. 1991, 1, 1-8.

26. Borre, M.; Offersen, B.V.; Nerstrøm, B.; Overgaard, J. Microvessel density predicts survival in prostate cancer patients subjected to watchful waiting. Br. J. Cancer 1998, 7, 940-944.

27. Hansen, S.; Grabau, D.A.; Sørensen, F.B.; Bak, M.; Rose, W.V.A.C. The prognostic value of angiogenesis by Chalkley counting in a confirmatory study design on 836 breast cancer patients. Clin. Cancer Res. 2000, 1, 139-146.

28. Borre, M.; Nerstrøm, B.; Overgaard, J. Association between immunohistochemical expression of vascular endothelial growth factor (VEGF), VEGF-expressing neuroendocrine-differentiated tumor cells, and outcome in prostate cancer patients subjected to watchful waiting. Clin. Cancer Res. 2000, 5, 1882-1890.

29. Gasparini, G. Clinical significance of determination of surrogate markers of angiogenesis in breast cancer. Crit. Rev. Oncol. 2001, 2, 97-114.

30. Robinson, S.P.; Rijken, P.F.J.W.; Howe, F.A.; McSheehy, P.M.J.; van der Sanden, B.P.J.; Heerschap, A.; Stubbs, M.; van der Kogel, A.J.; Griffiths, J.R. Tumor vascular architecture and function evaluated by non-invasive susceptibility MRI methods and immunohistochemistry. J. Magn. Reson. Imaging 2003, 4, 445-454.

31. Garcia-Barros, M.; Paris, F.; Cordon-Cardo, C.; Lyden, D.; Rafii, S.; Haimovitz-Friedman, A.; Fuks, Z.; Kolesnick, R. Tumor response to radiotherapy regulated by endothelial cell apoptosis. Science 2003, 5622, 1155-1159.

32. Horsman, M.R.; Nielsen, T.; Østergaard, L.; Overgaard, J. Radiation administered as a large single dose or in a fractionated schedule: Role of the tumour vasculature as a target for influencing response. Acta Oncol. 2006, 7, 876-880.

33. Miller, J.C.; Pien, H.H.; Sahani, D.; Sorensen, A.G.; Thrall, J.H. Imaging angiogenesis: Applications and potential for drug development. J. Natl. Cancer Inst. 2005, 3, 172-187.

34. Lassau, N.; Chebil, M.; Chami, L.; Bidault, S.; Girard, E.; Roche, A. Dynamic contrast-enhanced ultrasonography (DCE-US): A new tool for the early evaluation of antiangiogenic treatment. Target Oncol. 2010, 1, 53-58. 
35. Mason, R.P.; Zhao, D.; Liu, L.; Trawick, M.L.; Pinney, K.G. A perspective on vascular disrupting agents that interact with tubulin: preclinical tumor imaging and biological assessment. Integr. Biol. (Camb) 2011, 4, 375-387.

36. Tai, J.H.; Tessier, J.; Ryan, A.J.; Hoffman, L.; Chen, X.; Lee, T.Y. Assessment of acute antivascular effects of vandetanib with high-resolution dynamic contrast-enhanced computed tomographic imaging in a human colon tumor xenograft model in the nude rat. Neoplasia 2010, 9 , $697-707$.

37. Anderson, H.L.; Yap, J.T.; Miller, M.P.; Robbins, A.; Jones, T.; Price, P.M. Assessment of pharmacodynamic vascular response in a phase I trial of combretastatin A4 phosphate. J. Clin. Oncol. 2003, 15, 2823-2830.

38. Leach, M.O.; Brindle, K.M.; Evelhoch, J.L.; Griffiths, J.R.; Horsman, M.R.; Jackson, A.; Jayson, G.C.; Judson, I.R.; Knopp, M.V.; Maxwell, R.J.; et al. Pharmacodynamic/Pharmacokinetic Technologies Advisory Committee, Drug Development Office, Cancer Research UK The assessment of antiangiogenic and antivascular therapies in early-stage clinical trials using magnetic resonance imaging: issues and recommendations. Br. J. Cancer 2005, 9, 1599-1610.

39. Petersen, E.T.; Zimine, I.; Ho, Y.C.; Golay, X. Non-invasive measurement of perfusion: A critical review of arterial spin labelling techniques. Br. J. Radiol. 2006, 944, 688-701.

40. Jarnum, H.; Steffensen, E.G.; Knutsson, L.; Frund, E.T.; Simonsen, C.W.; Lundbye-Christensen, S.; Shankaranarayanan, A.; Alsop, D.C.; Jensen, F.T.; Larsson, E.M. Perfusion MRI of brain tumours: A comparative study of pseudo-continuous arterial spin labelling and dynamic susceptibility contrast imaging. Neuroradiology 2010, 4, 307-317.

41. Van Westen, D.; Petersen, E.T.; Wirestam, R.; Siemund, R.; Bloch, K.M.; Stahlberg, F.; Bjorkman-Burtscher, I.M.; Knutsson, L. Correlation between arterial blood volume obtained by arterial spin labelling and cerebral blood volume in intracranial tumours. Magma Magn. Reson. Mater. Phy. Biol. Med. 2011, 4, 211-223.

42. Østergaard, L.; Weisskoff, R.M.; Chesler, D.A.; Gyldensted, C.; Rosen, B.R. High resolution measurement of cerebral blood flow using intravascular tracer bolus passages. Part I: Mathematical approach and statistical analysis. Magn. Reson. Med. 1996, 5, 715-725.

43. Østergaard, L.; Sørensen, A.G.; Kwong, K.K.; Gyldensted, R.M. W. a. C.; Rosen, B.R. High resolution measurement of cerebral blood flow using intravascular tracer bolus passages. Part II: Experimental comparison and preliminary results. Magn. Reson. Med. 1996, 5, 726-736.

44. Kiselev, V.G.; Strecker, R.; Ziyeh, S.; Speck, O.; Hennig, J. Vessel size imaging in humans. Magn. Reson. Med. 2005, 3, 553-563.

45. Dennie, J.; Mandeville, J.B.; Boxerman, J.L.; Packard, S.D.; Rosen, B.R.; Weisskoff, R.M. NMR imaging of changes in vascular morphology due to tumor angiogenesis. Magn. Reson. Med. 1998, 6, 793-799.

46. Troprès, I.; Grimault, S.; Vaeth, A.; Grillon, E.; Julien, C.; Payen, J.F.; Lamalle, L.; Décorps, M. Vessel size imaging. Magn. Reson. Med. 2001, 3, 397-408.

47. Zahra, M.A.; Hollingsworth, K.G.; Sala, E.; Lomas, D.J.; Tan, L.T. Dynamic contrast-enhanced MRI as a predictor of tumour response to radiotherapy. Lancet Oncol 2007, 1, 63-74. 
48. Gadian, D.G.; Payne, J.A.; Bryant, D.J.; Young, I.R.; Carr, D.H.; Bydder, G.M. Gadolinium-DTPA as a contrast agent in MR imaging-Theoretical projections and practical observations. J. Comput. Assist. Tomogr. 1985, 2, 242-251.

49. Grossman, R.I.; Gonzalez-Scarano, F.; Atlas, S.W.; Galetta, S.; Silberberg, D.H. Multiple sclerosis: Gadolinium enhancement in MR imaging. Radiology 1986, 3, 721-725.

50. Miller, D.H.; Rudge, P.; Johnson, G.; Kendall, B.E.; Macmanus, D.G.; Moseley, I.F.; Barnes, D.; McDonald, W.I. Serial gadolinium enhanced magnetic resonance imaging in multiple sclerosis. Brain 1988, Pt 4, 927-939.

51. Pradel, C.; Siauve, N.; Bruneteau, G.; Clement, O.; de Bazelaire, C.; Frouin, F.; Wedge, S.R.; Tessier, J.L.; Robert, P.H.; Frija, G.; et al. Reduced capillary perfusion and permeability in human tumour xenografts treated with the VEGF signalling inhibitor ZD4190: An in vivo assessment using dynamic MR imaging and macromolecular contrast media. Magn. Reson. Imaging 2003, 8 , 845-851.

52. De Bazelaire, C.; Siauve, N.; Fournier, L.; Frouin, F.; Robert, P.; Clement, O.; de Kerviler, E.; Cuenod, C.A. Comprehensive model for simultaneous MRI determination of perfusion and permeability using a blood-pool agent in rats rhabdomyosarcoma. Eur. Radiol. 2005, 12, 2497-2505.

53. Sourbron, S.P.; Buckley, D.L. Tracer kinetic modelling in MRI: Estimating perfusion and capillary permeability. Phys. Med. Biol. 2012, 2, R1-R33.

54. Evelhoch, J.L. Key factors in the acquisition of contrast kinetic data for oncology. J. Magn. Reson. Imaging 1999, 3, 254-259.

55. Kety, S.S. The theory and applications of the exchange of inert gas at the lungs and tissues. Pharmacol. Rev. 1951, 3, 1-41.

56. Renkin, E.M. Transport of potassium-42 from blood to tissue in isolated mammalian skeletal muscles. Am. J. Physiol. 1959, 197, 1205-1210.

57. Crone, $\mathrm{C}$. The permeability of capillaries in various organs as determined by use of the "indicator diffusion" method. Acta Physiol. Scand. 1963, 58, 292-305.

58. Patlak, C.S.; Fenstermacher, J.D. Measurements of dog blood-brain transfer constants by ventriculocisternal perfusion. Am. J. Physiol. 1975, 4, 877-884.

59. Tofts, P.S. Modeling tracer kinetics in dynamic Gd-DTPA MR imaging. J. Magn. Reson. Imaging 1997, 1, 91-101.

60. Tofts, P.S.; Kermode, A.G. Measurement of the blood-brain barrier permeability and leakage space using dynamic MR imaging. 1. Fundamental concepts. Magn. Reson. Med. 1991, 2, 357-367.

61. Larsson, H.B.; Stubgaard, M.; Frederiksen, J.L.; Jensen, M.; Henriksen, O.; Paulson, O.B. Quantitation of blood-brain barrier defect by magnetic resonance imaging and gadolinium-DTPA in patients with multiple sclerosis and brain tumors. Magn. Reson. Med. 1990, 1, 117-131.

62. Brix, G.; Semmler, W.; Port, R.; Schad, L.R.; Layer, G.; Lorenz, W.J. Pharmacokinetic parameters in CNS Gd-DTPA enhanced MR imaging. J. Comput. Assist. Tomogr. 1991, 4, 621-628. 
63. Ewing, J.R.; Knight, R.A.; Nagaraja, T.N.; Yee, J.S.; Nagesh, V.; Whitton, P.A.; Li, L.; Fenstermacher, J.D. Patlak plots of Gd-DTPA MRI data yield blood-brain transfer constants concordant with those of 14C-sucrose in areas of blood-brain opening. Magn. Reson. Med. 2003, 2, 283-292.

64. Tofts, P.S.; Brix, G.; Buckley, D.L.; Evelhoch, J.L.; Henderson, E.; Knopp, M.V.; Larsson, H.B.; Lee, T.Y.; Mayr, N.A.; Parker, G.J.; et al. Estimating kinetic parameters from dynamic contrast-enhanced T(1)-weighted MRI of a diffusable tracer: standardized quantities and symbols. J. Magn. Reson. Imaging 1999, 3, 223-232.

65. Patlak, C.S.; Blasberg, R.G. Graphical evaluation of blood-to-brain transfer constants from multiple-time uptake data. Generalizations. J. Cereb. Blood Flow Metab. 1985, 4, 584-590.

66. Ewing, J.R.; Brown, S.L.; Lu, M.; Panda, S.; Ding, G.; Knight, R.A.; Cao, Y.; Jiang, Q.; Nagaraja, T.N.; Churchman, J.L.; et al. Model selection in magnetic resonance imaging measurements of vascular permeability: Gadomer in a 9L model of rat cerebral tumor. J. Cereb. Blood Flow Metab. 2006, 3, 310-320.

67. Roberts, T. Technical and practical considerations for permeability modeling of dynamic contrast enhanced MRI. Acad. Radiol. 2005, S34-S37.

68. Weinmann, H.J.; Laniado, M.; Mützel, W. Pharmacokinetics of GdDTPA/dimeglumine after intravenous injection into healthy volunteers. Physiol. Chem. Phys. Med. NMR 1984, 2, 167-172.

69. Wedeking, P.; Eaton, S.; Covell, D.G.; Nair, S.; Tweedle, M.F.; Eckelman, W.C. Pharmacokinetic analysis of blood distribution of intravenously administered 153Gd-labeled Gd(DTPA)2- and 99mTc(DTPA) in rats. Magn. Reson. Imaging 1990, 5, 567-575.

70. Maxwell, R.J.; Wilson, J.; Prise, V.E.; Vojnovic, B.; Rustin, G.J.; Lodge, M.A.; Tozer, G.M. Evaluation of the anti-vascular effects of combretastatin in rodent tumours by dynamic contrast enhanced MRI. NMR Biomed. 2002, 2, 89-98.

71. Furman-Haran, E.; Grobgeld, D.; Degani, H. Dynamic contrast-enhanced imaging and analysis at high spatial resolution of MCF7 human breast tumors. J. Magn. Reson. 1997, 2, 161-171.

72. Yang, C.; Karczmar, G.S.; Medved, M.; Stadler, W.M. Estimating the arterial input function using two reference tissues in dynamic contrast-enhanced MRI studies: Fundamental concepts and simulations. Magn. Reson. Med. 2004, 5, 1110-1117.

73. Yankeelov, T.E.; Luci, J.J.; Lepage, M.; Li, R.; Debusk, L.; Lin, P.C.; Price, R.R.; Gore, J.C. Quantitative pharmacokinetic analysis of DCE-MRI data without an arterial input function: A reference region model. Magn. Reson. Imaging 2005, 4, 519-529.

74. Turetschek, K.; Preda, A.; Novikov, V.; Brasch, R.C.; Weinmann, H.J.; Wunderbaldinger, P.; Roberts, T.P. Tumor microvascular changes in antiangiogenic treatment: Assessment by magnetic resonance contrast media of different molecular weights. J. Magn. Reson. Imaging 2004, 1, 138-144.

75. Brasch, R.; Turetschek, K. MRI characterization of tumors and grading angiogenesis using macromolecular contrast media: status report. Eur. J. Radiol. 2000, 3, 148-155.

76. Daldrup-Link, H.E.; Kaiser, A.; Helbich, T.; Werner, M.; Bjørnerud, A.; Link, T.M.; Rummeny, E.J. Macromolecular contrast medium (feruglose) versus small molecular contrast medium (gadopentetate) enhanced magnetic resonance imaging: differentiation of benign and malignant breast lesions. Acad. Radiol. 2003, 11, 1237-1246. 
77. Bentzen, L.; Vestergaard-Poulsen, P.; Nielsen, T.; Overgaard, J.; Bjørnerud, A.; Briley-Saebø, K.; Horsman, M.R.; Ostergaard, L. Intravascular contrast agent-enhanced MRI measuring contrast clearance and tumor blood volume and the effects of vascular modifiers in an experimental tumor. Int. J. Radiat. Oncol. Biol. Phys. 2005, 4, 1208-1215.

78. Brasch, R.; Pham, C.; Shames, D.; Roberts, T.; van Dijke, K.; van Bruggen, N.; Mann, J.; Ostrowitzki, S.; Melnyk, O. Assessing tumor angiogenesis using macromolecular MR imaging contrast media. J. Magn. Reson. Imaging 1997, 1, 68-74.

79. Pham, C.D.; Roberts, T.P.; Bruggen, N. v.; Melnyk, O.; Mann, J.; Ferrara, N.; Cohen, R.L.; Brasch, R.C. Magnetic resonance imaging detects suppression of tumor vascular permeability after administration of antibody to vascular endothelial growth factor. Cancer Invest. 1998, 4, 225-230.

80. Gossmann, A.; Helbich, T.H.; Mesiano, S.; Shames, D.M.; Wendland, M.F.; Roberts, T.P.; Ferrara, N.; Jaffe, R.B.; Brasch, R.C. Magnetic resonance imaging in an experimental model of human ovarian cancer demonstrating altered microvascular permeability after inhibition of vascular endothelial growth factor. Am. J. Obstet. Gynecol. 2000, 4, 956-963.

81. Gossmann, A.; Helbich, T.H.; Kuriyama, N.; Ostrowitzki, S.; Roberts, T.P.; Shames, D.M.; van Bruggen, N.; Wendland, M.F.; Israel, M.A.; Brasch, R.C. Dynamic contrast-enhanced magnetic resonance imaging as a surrogate marker of tumor response to anti-angiogenic therapy in a xenograft model of glioblastoma multiforme. J. Magn. Reson. Imaging 2002, 3, 233-240.

82. Daldrup-Link, H.E.; Okuhata, Y.; Wolfe, A.; Srivastav, S.; Øie, S.; Ferrara, N.; Cohen, R.L.; Shames, D.M.; Brasch, R.C. Decrease in tumor apparent permeability-surface area product to a MRI macromolecular contrast medium following angiogenesis inhibition with correlations to cytotoxic drug accumulation. Microcirculation 2004, 5, 387-396.

83. Preda, A.; Novikov, V.; Moglich, M.; Turetschek, K.; Shames, D.M.; Brasch, R.C.; Cavagna, F.M.; Roberts, T.P. MRI monitoring of Avastin antiangiogenesis therapy using B22956/1, a new blood pool contrast agent, in an experimental model of human cancer. J. Magn. Reson. Imaging 2004, 5, $865-873$.

84. Jahnke, K.; Muldoon, L.L.; Varallyay, C.G.; Lewin, S.J.; Kraemer, D.F.; Neuwelt, E.A. Bevacizumab and carboplatin increase survival and asymptomatic tumor volume in a glioma model. Neuro Oncol. 2009, 2, 142-150.

85. Bauerle, T.; Bartling, S.; Berger, M.; Schmitt-Graff, A.; Hilbig, H.; Kauczor, H.U.; Delorme, S.; Kiessling, F. Imaging anti-angiogenic treatment response with DCE-VCT, DCE-MRI and DWI in an animal model of breast cancer bone metastasis. Eur. J. Radiol. 2010, 2, 280-287.

86. Muldoon, L.L.; Gahramanov, S.; Li, X.; Marshall, D.J.; Kraemer, D.F.; Neuwelt, E.A. Dynamic magnetic resonance imaging assessment of vascular targeting agent effects in rat intracerebral tumor models. Neuro Oncol. 2011, 1, 51-60.

87. Keunen, O.; Johansson, M.; Oudin, A.; Sanzey, M.; Rahim, S.A.; Fack, F.; Thorsen, F.; Taxt, T.; Bartos, M.; Jirik, R.; et al. Anti-VEGF treatment reduces blood supply and increases tumor cell invasion in glioblastoma. Proc. Natl. Acad. Sci. USA 2011, 9, 3749-3754.

88. Fruth, K.; Weber, S.; Okcu, Y.; Noppens, R.; Klein, K.U.; Joest, E.; Hedrich, J.; Thilemann, S.; Pogorzelski, B.; Koutsimpelas, D.; et al. Increased basic fibroblast growth factor release and proliferation in xenotransplanted squamous cell carcinoma after combined irradiation/anti-vascular endothelial growth factor treatment. Oncol. Rep. 2012, 5, 1573-1579. 
89. Kiessling, F.; Farhan, N.; Lichy, M.P.; Vosseler, S.; Heilmann, M.; Krix, M.; Bohlen, P.; Miller, D.W.; Mueller, M.M.; Semmler, W.; et al. Dynamic contrast-enhanced magnetic resonance imaging rapidly indicates vessel regression in human squamous cell carcinomas grown in nude mice caused by VEGF receptor 2 blockade with DC101. Neoplasia 2004, 3, 213-223.

90. Hoff, B.A.; Bhojani, M.S.; Rudge, J.; Chenevert, T.L.; Meyer, C.R.; Galban, S.; Johnson, T.D.; Leopold, J.S.; Rehemtulla, A.; Ross, B.D.; et al. DCE and DW-MRI monitoring of vascular disruption following VEGF-Trap treatment of a rat glioma model. NMR Biomed. 2012, 25, 935-942.

91. Turetschek, K.; Preda, A.; Floyd, E.; Shames, D.M.; Novikov, V.; Roberts, T.P.; Wood, J.M.; $\mathrm{Fu}$, Y.; Carter, W.O.; Brasch, R.C. MRI monitoring of tumor response following angiogenesis inhibition in an experimental human breast cancer model. Eur. J. Nucl. Med. Mol. Imaging 2003, 3, 448-455.

92. Rudin, M.; McSheehy, P.M.; Allegrini, P.R.; Rausch, M.; Baumann, D.; Becquet, M.; Brecht, K.; Brueggen, J.; Ferretti, S.; Schaeffer, F.; et al. PTK787/ZK222584, a tyrosine kinase inhibitor of vascular endothelial growth factor receptor, reduces uptake of the contrast agent GdDOTA by murine orthotopic B16/BL6 melanoma tumours and inhibits their growth in vivo. NMR Biomed. 2005, 5, 308-321.

93. Ali, M.M.; Janic, B.; Babajani-Feremi, A.; Varma, N.R.; Iskander, A.S.; Anagli, J.; Arbab, A.S. Changes in vascular permeability and expression of different angiogenic factors following anti-angiogenic treatment in rat glioma. PLoS One 2010, 1, e8727.

94. Drevs, J.; Muller-Driver, R.; Wittig, C.; Fuxius, S.; Esser, N.; Hugenschmidt, H.; Konerding, M.A.; Allegrini, P.R.; Wood, J.; Hennig, J.; et al. PTK787/ZK 222584, a specific vascular endothelial growth factor-receptor tyrosine kinase inhibitor, affects the anatomy of the tumor vascular bed and the functional vascular properties as detected by dynamic enhanced magnetic resonance imaging. Cancer Res. 2002, 14, 4015-4022.

95. Marzola, P.; Degrassi, A.; Calderan, L.; Farace, P.; Nicolato, E.; Crescimanno, C.; Sandri, M.; Giusti, A.; Pesenti, E.; Terron, A.; et al. Early antiangiogenic activity of SU11248 evaluated in vivo by dynamic contrast-enhanced magnetic resonance imaging in an experimental model of colon carcinoma. Clin. Cancer Res. 2005, 16, 5827-5832.

96. Casneuf, V.F.; Delrue, L.; van Damme, N.; Demetter, P.; Robert, P.; Corot, C.; Duyck, P.; Ceelen, W.; Boterberg, T.; Peeters, M. Noninvasive monitoring of therapy-induced microvascular changes in a pancreatic cancer model using dynamic contrast-enhanced magnetic resonance imaging with P846, a new low-diffusible gadolinium-based contrast agent. Radiat. Res. 2011, 1, 10-20.

97. Marzola, P.; Degrassi, A.; Calderan, L.; Farace, P.; Crescimanno, C.; Nicolato, E.; Giusti, A.; Pesenti, E.; Terron, A.; Sbarbati, A.; et al. In vivo assessment of antiangiogenic activity of SU6668 in an experimental colon carcinoma model. Clin. Cancer Res. 2004, 2, 739-750.

98. Farace, P.; Galie, M.; Merigo, F.; Daducci, A.; Calderan, L.; Nicolato, E.; Degrassi, A.; Pesenti, E.; Sbarbati, A.; Marzola, P. Inhibition of tyrosine kinase receptors by SU6668 promotes abnormal stromal development at the periphery of carcinomas. Br. J. Cancer 2009, 10, 1575-1580.

99. Checkley, D.; Tessier, J.J.; Kendrew, J.; Waterton, J.C.; Wedge, S.R. Use of dynamic contrast-enhanced MRI to evaluate acute treatment with ZD6474, a VEGF signalling inhibitor, in PC-3 prostate tumours. Br. J. Cancer 2003, 10, 1889-1895. 
100. Wilmes, L.J.; Pallavicini, M.G.; Fleming, L.M.; Gibbs, J.; Wang, D.; Li, K.L.; Partridge, S.C.; Henry, R.G.; Shalinsky, D.R.; Hu-Lowe, D.; et al. AG-013736, a novel inhibitor of VEGF receptor tyrosine kinases, inhibits breast cancer growth and decreases vascular permeability as detected by dynamic contrast-enhanced magnetic resonance imaging. Magn. Reson. Imaging 2007, 3, 319-327.

101. Dafni, H.; Kim, S.J.; Bankson, J.A.; Sankaranarayanapillai, M.; Ronen, S.M. Macromolecular dynamic contrast-enhanced (DCE)-MRI detects reduced vascular permeability in a prostate cancer bone metastasis model following anti-platelet-derived growth factor receptor (PDGFR) therapy, indicating a drop in vascular endothelial growth factor receptor (VEGFR) activation. Magn. Reson. Med. 2008, 4, 822-833.

102. Kamoun, W.S.; Ley, C.D.; Farrar, C.T.; Duyverman, A.M.; Lahdenranta, J.; Lacorre, D.A.; Batchelor, T.T.; di Tomaso, E.; Duda, D.G.; Munn, L.L.; et al. Edema control by cediranib, a vascular endothelial growth factor receptor-targeted kinase inhibitor, prolongs survival despite persistent brain tumor growth in mice. J. Clin. Oncol. 2009, 15, 2542-2552.

103. Merz, M.; Komljenovic, D.; Zwick, S.; Semmler, W.; Bauerle, T. Sorafenib tosylate and paclitaxel induce anti-angiogenic, anti-tumour and anti-resorptive effects in experimental breast cancer bone metastases. Eur. J. Cancer 2011, 2, 277-286.

104. Bhujwalla, Z.M.; Artemov, D.; Natarajan, K.; Solaiyappan, M.; Kollars, P.; Kristjansen, P.E. Reduction of vascular and permeable regions in solid tumors detected by macromolecular contrast magnetic resonance imaging after treatment with antiangiogenic agent TNP-470. Clin. Cancer Res. 2003, 1, 355-362.

105. Lane, H.A.; Wood, J.M.; McSheehy, P.M.; Allegrini, P.R.; Boulay, A.; Brueggen, J.; Littlewood-Evans, A.; Maira, S.M.; Martiny-Baron, G.; Schnell, C.R.; et al. mTOR inhibitor RAD001 (everolimus) has antiangiogenic/vascular properties distinct from a VEGFR tyrosine kinase inhibitor. Clin. Cancer Res. 2009, 5, 1612-1622.

106. Yang, J.; Kim, J.H.; Im, G.H.; Heo, H.; Yoon, S.; Lee, J.; Lee, J.H.; Jeon, P. Evaluation of antiangiogenic effects of a new synthetic candidate drug KR-31831 on xenografted ovarian carcinoma using dynamic contrast enhanced MRI. Korean J. Radiol. 2011, 5, 602-610.

107. Ansiaux, R.; Baudelet, C.; Jordan, B.F.; Beghein, N.; Sonveaux, P.; de Wever, J.; Martinive, P.; Gregoire, V.; Feron, O.; Gallez, B. Thalidomide radiosensitizes tumors through early changes in the tumor microenvironment. Clin. Cancer Res. 2005, 2, 743-750.

108. Cyran, C.C.; Sennino, B.; Chaopathomkul, B.; Fu, Y.; Rogut, V.S.; Shames, D.M.; Wendland, M.F.; McDonald, D.M.; Brasch, R.C. Magnetic resonance imaging for monitoring the effects of thalidomide on experimental human breast cancers. Eur. Radiol. 2009, 1, 121-131.

109. Zhao, D.; Jiang, L.; Hahn, E.W.; Mason, R.P. Continuous low-dose (metronomic) chemotherapy on rat prostate tumors evaluated using MRI in vivo and comparison with histology. Neoplasia 2005, 7 , $678-687$.

110. Lee, D.F.; Hung, M.C. All roads lead to mTOR: Integrating inflammation and tumor angiogenesis. Cell. Cycle 2007, 24, 3011-3014.

111. Beauregard, D.A.; Thelwall, P.E.; Chaplin, D.J.; Hill, S.A.; Adams, G.E.; Brindle, K.M. Magnetic resonance imaging and spectroscopy of combretastatin A4 prodrug-induced disruption of tumour perfusion and energetic status. Br. J. Cancer 1998, 11, 1761-1767. 
112. Beauregard, D.A.; Hill, S.A.; Chaplin, D.J.; Brindle, K.M. The susceptibility of tumors to the antivascular drug combretastatin A4 phosphate correlates with vascular permeability. Cancer Res. 2001, 18, 6811-6815.

113. Beauregard, D.A.; Pedley, R.B.; Hill, S.A.; Brindle, K.M. Differential sensitivity of two adenocarcinoma xenografts to the anti-vascular drugs combretastatin A4 phosphate and 5,6-dimethylxanthenone-4-acetic acid, assessed using MRI and MRS. NMR Biomed. 2002, 2, 99-105.

114. Salmon, H.W.; Siemann, D.W. Effect of the second-generation vascular disrupting agent OXi4503 on tumor vascularity. Clin. Cancer Res. 2006, 13, 4090-4094.

115. Lankester, K.J.; Maxwell, R.J.; Pedley, R.B.; Dearling, J.L.; Qureshi, U.A.; El-Emir, E.; Hill, S.A.; Tozer, G.M. Combretastatin A-4-phosphate effectively increases tumor retention of the therapeutic antibody, 131I-A5B7, even at doses that are sub-optimal for vascular shut-down. Int. J. Oncol. 2007, 2, 453-460.

116. Salmon, B.A.; Salmon, H.W.; Siemann, D.W. Monitoring the treatment efficacy of the vascular disrupting agent CA4P. Eur. J. Cancer 2007, 10, 1622-1629.

117. Nielsen, T.; Murata, R.; Maxwell, R.J.; Stødkilde-Jørgensen, H.; Ostergaard, L.; Horsman, M.R. Preclinical studies to predict efficacy of vascular changes induced by combretastatin a-4 disodium phosphate in patients. Int. J. Radiat. Oncol. Biol. Phys. 2008, 3, 859-866.

118. Zhao, D.; Richer, E.; Antich, P.P.; Mason, R.P. Antivascular effects of combretastatin A4 phosphate in breast cancer xenograft assessed using dynamic bioluminescence imaging and confirmed by MRI. FASEB J. 2008, 7, 2445-2451.

119. Nielsen, T.; Mouridsen, K.; Maxwell, R.J.; Stødkilde-Jørgensen, H.; Østergaard, L.; Horsman, M.R. Segmentation of dynamic contrast enhanced magnetic resonance imaging data. Acta Oncol. 2008, 7, 1265-1270.

120. Nielsen, T.; Murata, R.; Maxwell, R.J.; Stodkilde-Jorgensen, H.; Ostergaard, L.; Ley, C.D.; Kristjansen, P.E.; Horsman, M.R. Non-invasive imaging of combretastatin activity in two tumor models: Association with invasive estimates. Acta Oncol. 2010, 7, 906-913.

121. Bohndiek, S.E.; Kettunen, M.I.; Hu, D.E.; Witney, T.H.; Kennedy, B.W.; Gallagher, F.A.; Brindle, K.M. Detection of tumor response to a vascular disrupting agent by hyperpolarized 13C magnetic resonance spectroscopy. Mol. Cancer. Ther. 2010, 12, 3278-3288.

122. Galbraith, S.M.; Maxwell, R.J.; Lodge, M.A.; Tozer, G.M.; Wilson, J.; Taylor, N.J.; Stirling, J.J.; Sena, L.; Padhani, A.R.; Rustin, G.J. S. Combretastatin A4 phosphate has tumor antivascular activity in rat and man as demonstrated by dynamic magnetic resonance imaging. J. Clin. Oncol. 2003, 15, 2831-2842.

123. Zhao, D.; Jiang, L.; Hahn, E.W.; Mason, R.P. Tumor physiologic response to combretastatin A4 phosphate assessed by MRI. Int. J. Radiat. Oncol. Biol. Phys. 2005, 3, 872-880.

124. Thoeny, H.C.; Keyzer, F.D.; Vandecaveye, V.; Chen, F.; Sun, X.; Bosmans, H.; Hermans, R.; Verbeken, E.K.; Boesch, C.; Marchal, G.; et al. Effect of vascular targeting agent in rat tumor model: Dynamic contrast-enhanced versus diffusion-weighted MR imaging. Radiology 2005, 2, 492-499. 
125. Wang, H.; Cona, M.M.; Chen, F.; Yu, J.; Feng, Y.; Li, J.; Keyzer, F.D.; Marchal, G.; Ni, Y. Comparison of two vascular-disrupting agents at a clinically relevant dose in rodent liver tumors with multiparametric magnetic resonance imaging biomarkers. Anticancer Drugs 2012, 1, 12-21.

126. Evelhoch, J.L.; LoRusso, P.M.; He, Z.; DelProposto, Z.; Polin, L.; Corbett, T.H.; Langmuir, P.; Wheeler, C.; Stone, A.; Leadbetter, J.; et al. Magnetic resonance imaging measurements of the response of murine and human tumors to the vascular-targeting agent ZD6126. Clin. Cancer Res. 2004, 11, 3650-3657.

127. Vogel-Claussen, J.; Gimi, B.; Artemov, D.; Bhujwalla, Z.M. Diffusion-weighted and macromolecular contrast enhanced MRI of tumor response to antivascular therapy with ZD6126. Cancer. Biol. Ther. 2007, 9, 1469-1475.

128. Robinson, S.P.; McIntyre, D.J.O.; Checkley, D.; Tessier, J.J.; Howe, F.A.; Griffiths, J.R.; Ashton, S.E.; Ryan, A.J.; Blakey, D.C.; Waterton, J.C. Tumour dose response to the antivascular agent ZD6126 assessed by magnetic resonance imaging. Br. J. Cancer 2003, 10, 1592-1597.

129. McIntyre, D.J.; Robinson, S.P.; Howe, F.A.; Griffiths, J.R.; Ryan, A.J.; Blakey, D.C.; Peers, I.S.; Waterton, J.C. Single dose of the antivascular agent, ZD6126 ( $\mathrm{N}$-acetylcolchinol- $O$-phosphate), reduces perfusion for at least 96 hours in the GH3 prolactinoma rat tumor model. Neoplasia 2004, 2, 150-157.

130. Bradley, D.P.; Tessier, J.J.; Ashton, S.E.; Waterton, J.C.; Wilson, Z.; Worthington, P.L.; Ryan, A.J. Correlation of MRI biomarkers with tumor necrosis in Hras5 tumor xenograft in athymic rats. Neoplasia 2007, 5, 382-391.

131. Wang, H.; Li, J.; Chen, F.; De Keyzer, F.; Yu, J.; Feng, Y.; Nuyts, J.; Marchal, G.; Ni, Y. Morphological, functional and metabolic imaging biomarkers: Assessment of vascular-disrupting effect on rodent liver tumours. Eur. Radiol. 2010, 8, 2013-2026.

132. Bertelsen, L.B.; Shen, Y.Y.; Nielsen, T.; Stodkilde-Jorgensen, H.; Lloyd, G.K.; Siemann, D.W.; Horsman, M.R. Vascular effects of plinabulin (NPI-2358) and the influence on tumour response when given alone or combined with radiation. Int. J. Radiat. Biol. 2011, 11, 1126-1134.

133. Durrant, D.; Corwin, F.; Simoni, D.; Zhao, M.; Rudek, M.A.; Salloum, F.N.; Kukreja, R.C.; Fatouros, P.P.; Lee, R.M. cis-3,4',5-Trimethoxy-3'-aminostilbene disrupts tumor vascular perfusion without damaging normal organ perfusion. Cancer Chemother. Pharmacol. 2009, 2, 191-200.

134. Natsume, T.; Watanabe, J.; Ogawa, K.; Yasumura, K.; Kobayashi, M. Tumor-specific antivascular effect of TZT-1027 (Soblidotin) elucidated by magnetic resonance imaging and confocal laser scanning microscopy. Cancer. Sci. 2007, 4, 598-604.

135. Luo, Y.; Hradil, V.P.; Frost, D.J.; Rosenberg, S.H.; Gordon, G.B.; Morgan, S.J.; Gagne, G.D.; Cox, B.F.; Tahir, S.K.; Fox, G.B. ABT-751, a novel tubulin-binding agent, decreases tumor perfusion and disrupts tumor vasculature. Anticancer Drugs 2009, 6, 483-492.

136. Seshadri, M.; Spernyak, J.A.; Mazurchuk, R.; Camacho, S.H.; Oseroff, A.R.; Cheney, R.T.; Bellnier, D.A. Tumor vascular response to photodynamic therapy and the antivascular agent 5,6-dimethylxanthenone-4-acetic acid: implications for combination therapy. Clin. Cancer Res. 2005, 11, 4241-4250. 
137. Seshadri, M.; Mazurchuk, R.; Spernyak, J.A.; Bhattacharya, A.; Rustum, Y.M.; Bellnier, D.A. Activity of the vascular-disrupting agent 5,6-dimethylxanthenone-4-acetic acid against human head and neck carcinoma xenografts. Neoplasia 2006, 7, 534-542.

138. Seshadri, M.; Spernyak, J.A.; Maiery, P.G.; Cheney, R.T.; Mazurchuk, R.; Bellnier, D.A. Visualizing the acute effects of vascular-targeted therapy in vivo using intravital microscopy and magnetic resonance imaging: Correlation with endothelial apoptosis, cytokine induction, and treatment outcome. Neoplasia 2007, 2, 128-135.

139. Seshadri, M.; Bellnier, D.A.; Cheney, R.T. Assessment of the early effects of 5,6-dimethylxanthenone-4-acetic acid using macromolecular contrast media-enhanced magnetic resonance imaging: Ectopic versus orthotopic tumors. Int. J. Radiat. Oncol. Biol. Phys. 2008, 4, 1198-1207.

140. Seshadri, M.; Ciesielski, M.J. MRI-based characterization of vascular disruption by 5,6-dimethylxanthenone-acetic acid in gliomas. J. Cereb. Blood Flow Metab. 2009, 8, 1373-1382.

141. Seshadri, M.; Toth, K. Acute vascular disruption by 5,6-dimethylxanthenone-4-acetic Acid in an orthotopic model of human head and neck cancer. Transl. Oncol. 2009, 3, 121-127.

142. Seshadri, M.; Sacadura, N.T.; Coulthard, T. Monitoring antivascular therapy in head and neck cancer xenografts using contrast-enhanced MR and US imaging. Angiogenesis 2011, 4, 491-501.

143. Barbera, M.; Kettunen, M.I.; Caputo, A.; Hu, D.E.; Gobbi, S.; Brindle, K.M.; Carrara, M. Immune-modulating and anti-vascular activities of two xanthenone acetic acid analogues: A comparative study to DMXAA. Int. J. Oncol. 2009, 1, 273-279.

144. McPhail, L.D.; McIntyre, D.J.; Ludwig, C.; Kestell, P.; Griffiths, J.R.; Kelland, L.R.; Robinson, S.P. Rat tumor response to the vascular-disrupting agent 5,6-dimethylxanthenone-4-acetic acid as measured by dynamic contrast-enhanced magnetic resonance imaging, plasma 5-hydroxyindoleacetic acid levels, and tumor necrosis. Neoplasia 2006, 3, 199-206.

145. Tang, J.S.; Choy, G.; Bernardo, M.; Thomasson, D.; Libutti, S.K.; Choyke, P.L. Dynamic contrast-enhanced magnetic resonance imaging in the assessment of early response to tumor necrosis factor alpha in a colon carcinoma model. Invest. Radiol. 2006, 9, 691-696.

146. Haney, C.R.; Parasca, A.D.; Fan, X.; Bell, R.M.; Zamora, M.A.; Karczmar, G.S.; Mauceri, H.J.; Halpern, H.J.; Weichselbaum, R.R.; Pelizzari, C.A. Characterization of response to radiation mediated gene therapy by means of multimodality imaging. Magn. Reson. Med. 2009, 2, $348-356$.

147. Kiessling, F.; Huber, P.E.; Grobholz, R.; Heilmann, M.; Meding, J.; Lichy, M.P.; Fink, C.; Krix, M.; Peschke, P.; Schlemmer, H. Dynamic magnetic resonance tomography and proton magnetic resonance spectroscopy of prostate cancers in rats treated by radiotherapy. Invest. Radiol. 2004, 1, 34-44.

148. De Keyzer, F.; Vandecaveye, V.; Thoeny, H.; Chen, F.; Ni, Y.; Marchal, G.; Hermans, R.; Nuyts, S.; Landuyt, W.; Bosmans, H. Dynamic contrast-enhanced and diffusion-weighted MRI for early detection of tumoral changes in single-dose and fractionated radiotherapy: Evaluation in a rat rhabdomyosarcoma model. Eur. Radiol. 2009, 11, 2663-2671. 
149. Zilberstein, J.; Schreiber, S.; Bloemers, M.C.; Bendel, P.; Neeman, M.; Schechtman, E.; Kohen, F.; Scherz, A.; Salomon, Y. Antivascular treatment of solid melanoma tumors with bacteriochlorophyll-serine-based photodynamic therapy. Photochem. Photobiol. 2001, 3, $257-266$.

150. Eichhorn, M.E.; Becker, S.; Strieth, S.; Werner, A.; Sauer, B.; Teifel, M.; Ruhstorfer, H.; Michaelis, U.; Griebel, J.; Brix, G.; et al. Paclitaxel encapsulated in cationic lipid complexes (MBT-0206) impairs functional tumor vascular properties as detected by dynamic contrast enhanced magnetic resonance imaging. Cancer. Biol. Ther. 2006, 1, 89-96.

151. Eichhorn, M.E.; Luedemann, S.; Strieth, S.; Papyan, A.; Ruhstorfer, H.; Haas, H.; Michaelis, U.; Sauer, B.; Teifel, M.; Enders, G.; et al. Cationic lipid complexed camptothecin (EndoTAG-2) improves antitumoral efficacy by tumor vascular targeting. Cancer. Biol. Ther. 2007, 6, 920-929.

152. O’Connor, J.P.; Jackson, A.; Parker, G.J.; Roberts, C.; Jayson, G.C. Dynamic contrast-enhanced MRI in clinical trials of antivascular therapies. Nat. Rev. Clin. Oncol. 2012, 3, 167-177.

(C) 2012 by the authors; licensee MDPI, Basel, Switzerland. This article is an open access article distributed under the terms and conditions of the Creative Commons Attribution license (http://creativecommons.org/licenses/by/3.0/). 